AperTO - Archivio Istituzionale Open Access dell'Università di Torino

Sox 2 conditional mutation in mouse causes ataxic symptoms, cerebellar vermis hypoplasia, and postnatal defects of Bergmann glia

This is a pre print version of the following article:

Original Citation:

Availability:

This version is available http://hdl.handle.net/2318/1668960

since 2018-08-30T12:38:46Z

Published version:

DOI:10.1002/glia.23448

Terms of use:

Open Access

Anyone can freely access the full text of works made available as "Open Access". Works made available under a Creative Commons license can be used according to the terms and conditions of said license. Use of all other works requires consent of the right holder (author or publisher) if not exempted from copyright protection by the applicable law. 


\section{Sox 2 conditional mutation in mouse causes ataxic symptoms, cerebellar vermis hypoplasia, and postnatal defects of Bergmann glia}

\begin{tabular}{|c|c|}
\hline Journal: & GLIA \\
\hline Manuscript ID & GLIA-00489-2017.R1 \\
\hline Wiley - Manuscript type: & Original Research Article \\
\hline Date Submitted by the Author: & $\mathrm{n} / \mathrm{a}$ \\
\hline Complete List of Authors: & $\begin{array}{l}\text { Cerrato, Valentina; Universita degli Studi di Torino Dipartimento di } \\
\text { Neuroscienze, Neuroscience Institute Cavalieri Ottolenghi (NICO) } \\
\text { Mercurio, Sara; Università degli Studi di Milano-Bicocca, Dipartimento di } \\
\text { Biotecnologie e Bioscienze } \\
\text { Leto, Ketty; Universita degli Studi di Torino Dipartimento di Neuroscienze, } \\
\text { Neuroscience Institute Cavalieri Ottolenghi (NICO) } \\
\text { Fucà, Elisa; Universita degli Studi di Torino Dipartimento di Neuroscienze, } \\
\text { Neuroscience Institute Cavalieri Ottolenghi (NICO) } \\
\text { Hoxha, Eriola; Universita degli Studi di Torino Dipartimento di } \\
\text { Neuroscienze, Neuroscience Institute Cavalieri Ottolenghi (NICO) } \\
\text { Bottes, Sara; Università degli Studi di Milano-Bicocca, Dipartimento di } \\
\text { Biotecnologie e Bioscienze } \\
\text { Pagin, Miriam; University of Milano-Bicocca, Department of Biotechnology } \\
\text { and Biosciences } \\
\text { Milanese, Marco; University of Genova, Department of Pharmacy, } \\
\text { Pharmacology and Toxicology Unit } \\
\text { Ngan, Chew-Yee; The Jackson Laboratory for Genomic Medicine } \\
\text { Concina, Giulia; Universita degli Studi di Torino Dipartimento di } \\
\text { Neuroscienze, Neuroscience Institute Cavalieri Ottolenghi (NICO) } \\
\text { Ottolenghi, Sergio; Università degli Studi di Milano-Bicocca, Dipartimento } \\
\text { di Biotecnologie e Bioscienze } \\
\text { Wei, Chia-Lin; The Jackson Laboratory for Genomic Medicine } \\
\text { Bonanno, Giambattista; University of Genova, Department of Pharmacy, } \\
\text { Pharmacology and Toxicology Unit } \\
\text { Pavesi, Giulio; University of Milano, Department of Biosciences } \\
\text { Tempia, Filippo; Universita degli Studi di Torino Dipartimento di } \\
\text { Neuroscienze, Neuroscience Institute Cavalieri Ottolenghi (NICO) } \\
\text { Buffo, Annalisa; University of Turin, Department of Neuroscience } \\
\text { Neuroscience Institute Cavalieri Ottolenghi (NICO) } \\
\text { NICOLIS, SILVIA; Università degli Studi di Milano-Bicocca, Dipartimento di } \\
\text { Biotecnologie e Bioscienze }\end{array}$ \\
\hline Key Words: & Sox2, cerebellum, ataxia, Bergmann glia, mouse genetic models \\
\hline
\end{tabular}


Supplementary Table 3

\section{SCHOLARONE ${ }^{m}$ \\ Manuscripts}

John Wiley \& Sons, Inc. 


\section{Sox2 conditional mutation in mouse causes ataxic symptoms, cerebellar vermis hypoplasia, and postnatal defects of Bergmann glia}

Running title: Sox2 requirement in Bergmann glia

Valentina Cerrato ${ }^{1 *}$, Sara Mercurio ${ }^{2 *}$, Ketty Leto ${ }^{1 *}$, Elisa Fucà ${ }^{1}$, Eriola Hoxha ${ }^{1}$, Sara Bottes ${ }^{2}$, Miriam Pagin ${ }^{2}$, Marco Milanese ${ }^{3}$, Chew-Yee Ngan 4 , Giulia Concina ${ }^{1}$, Sergio Ottolenghi ${ }^{2}$, ChiaLin Wei ${ }^{4}$, Giambattista Bonanno ${ }^{3}$, Giulio Pavesi ${ }^{5}$, Filippo Tempia ${ }^{1}$, Annalisa Buffo ${ }^{1 \#}$ and Silvia K. Nicolis ${ }^{2 \#}$

${ }^{1}$ Department of Neuroscience Rita Levi-Montalcini, University of Torino, Neuroscience Institute Cavalieri Ottolenghi (NICO), Regione Gonzole, 10, 10043 Orbassano (Torino), Italy ${ }^{2}$ Department of Biotechnology and Biosciences, University of Milano-Bicocca, piazza della Scienza 2, 20126 Milano, Italy ${ }^{3}$ Department of Pharmacy, Pharmacology and Toxicology Unit and Center of Excellence for Biomedical Research, University of Genova, Viale Cembrano 4, 16148, Genoa, Italy.

4The Jackson Laboratory for Genomic Medicine, Farmington, CT, USA

${ }^{5}$ Department of Biosciences, University of Milano, 20100 Italy

* V.C., S.M. and K.L. should be considered joint first authors

\#A.B. and S.K.N. should be considered joint senior and corresponding authors

Corresponding authors:

Annalisa Buffo

Department of Neuroscience Rita Levi-Montalcini, University of Turin

Neuroscience Institute Cavalieri Ottolenghi (NICO)

Regione Gonzole, 10

10043 Orbassano (Torino), Italy

annalisa.buffo@unito.it

Silvia K. Nicolis

Department of Biotechnology and Biosciences,

University of Milano-Bicocca

piazza della Scienza 2

20126 Milano, Italy

silvia.nicolis@unimib.it

Acknowledgements: The Nicolis laboratory was supported by grants from Telethon (GGP12152), the European Community (ERANET-NEURON ImprovVision) and AIRC (IG16016). The Buffo laboratory was supported by local funds of the University of Turin and by Ministero dell'Istruzione, dell'Università e della Ricerca - MIUR project "Dipartimenti di Eccellenza 2018 - 2022" to Dept. of Neuroscience Rita Levi Montalcini.

Dedication. We dedicate this paper to the dear memory of our colleague and friend Ferdinando Rossi, whose insight and enthusiasm live on by our side. 
Conflict of interest: The authors declare no competing financial interest.

Total word count: 12905

Number of words for Abstract: 226

Number of words for Introduction: 446

Number of words for Materials and Methods: 3206

Number of words for Results: 2897

Number of words for Discussion: 1542

Number of words for References: 1782

Number of words for Figure Legends: 2059 


\section{Abstract}

Sox2 is a transcription factor active in the nervous system, within different cell types, ranging from radial glia neural stem cells to a few specific types of differentiated glia and neurons. Mutations in the human SOX2 transcription factor gene cause various central nervous system (CNS) abnormalities, involving hippocampus and eye defects, as well as ataxia. Conditional Sox2 mutation in mouse, with different Cre transgenes, previously recapitulated different essential features of the disease, such as hippocampus and eye defects. In the cerebellum, Sox2 is active from early embryogenesis in the neural progenitors of the cerebellar primordium; Sox2 expression is maintained, postnatally, within Bergmann glia (BG), a differentiated cell type essential for Purkinje neurons functionality and correct motor control. By performing Sox2 Cre-mediated ablation in the developingand postnatal mouse cerebellum, we reproduced ataxia features. Embryonic Sox2 deletion (with Wnt1Cre) leads to reduction of the cerebellar vermis, known to be commonly related to ataxia, preceded by deregulation of Otx2 and Gbx2, critical regulators of vermis development. Postnatally, BG is progressively disorganized, mislocalized, and reduced in mutants. Sox2 postnatal deletion, specifically induced in glia (with GLAST-CreERT2), reproduces the BG defect, and causes (milder) ataxic features. Our results define a role for Sox2 in cerebellar function and development, and identify a functional requirement for Sox2 within postnatal BG, of potential relevance for ataxia in mouse mutants, and in human patients.

\section{Key words:}

Sox2, cerebellum, ataxia, Bergmann glia, mouse genetic models, transcription factors 


\section{Table of contents image}

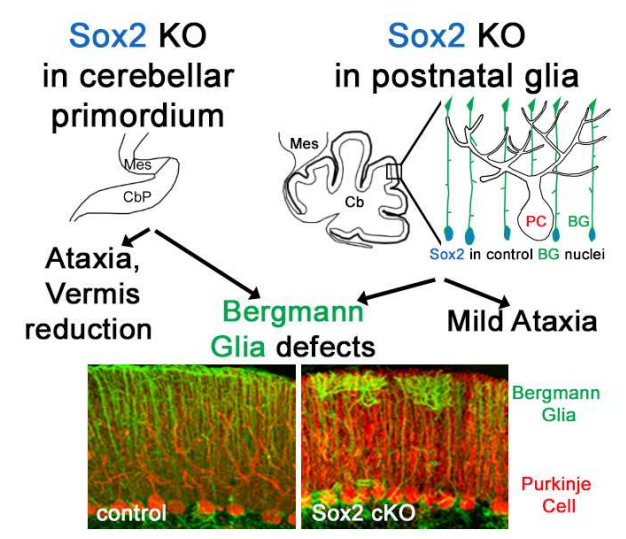

Main points

-Deletion of Sox2 in the cerebellar primordium leads to ataxic symptoms, with vermis hypoplasia and Bergmann glia dysmorphology and displacement

-Postnatal Sox2 deletion in glia causes mild ataxia with Bergmann glia defects 


\section{Introduction}

The Sox2 transcription factor is widely expressed in the developing central nervous system (CNS), from early embryogenesis (Bertolini, 2016; Pevny \& Nicolis, 2010). In humans, Sox2 heterozygous mutations lead to a spectrum of CNS defects, including eye defects, hippocampal reduction, seizures, as well as motor control defects and ataxia (Bertolini, 2016; Dennert et al., 2017; Ragge et al., 2005; Sisodiya et al., 2006). In mouse, complete Sox2 loss is early embryonic lethal (Avilion et al., 2003); by conditional knock-outs and hypomorphic mutants, we and others demonstrated that Sox2 loss leads to important CNS defects, affecting the eye, the developing ventral forebrain, and the hippocampus. Most of these defects arise as a consequence of the loss of neural stem cells (represented by radial glia), although in some cases specific glial or neuronal types have been involved (Cavallaro et al., 2008; Favaro et al., 2009; A. Ferri et al., 2013; A. L. Ferri et al., 2004; Pevny \& Nicolis, 2010).

Ataxia is a motor control defect, depending on cerebellar abnormalities, and is often the consequence of inherited genetic defects observed in man (Basson \& Wingate, 2013; Leto et al., 2016). While the genetic defects primarily operates in neurons in most types of ataxias, at least in two cases (SCA1, SCA7) Bergmann glia (BG), a specialized cerebellar glia essential for Purkinje neurons functionality, critically contributes to the defect; the BG dysfunction affects, in a non-cell-autonomous way, the functions of the adjacent Purkinje neuronal cells (PC), which are responsible for the functional defects (Buffo \& Rossi, 2013; Custer et al., 2006; Shiwaku et al., 2010). While the primary genetic defect is well defined, the network of gene regulation and protein interactions downstream to it are not yet well understood. 
Previous studies of hypomorphic Sox2 mutants demonstrated motor abnormalities (Ferri 2004); in this work, we investigated the possibility that Sox2 conditional ablation in mouse reproduces some of the ataxic features demonstrated in human patients. To this end, we ablated Sox2 either prenatally, or postnatally, within the cerebellum, a CNS region essential in the control of movement, whose disfunction leads to ataxias (Basson \& Wingate, 2013; Leto et al., 2016). We report that prenatal Sox2 loss in the developing midbrain-hindbrain region (via Wnt-1-Cre-mediated deletion) leads to a reduction of the cerebellar vermis at birth, and, postnatally, to progressive disorganization, mislocalization and reduction of BG, functionally accompanied by ataxia. BG retains Sox2 expression postnatally, and we find that postnatal deletion of Sox2 in glia (via GLAST-CreERT2) also leads to BG disorganization, mislocalization and reduction. Our findings point to a novel role for Sox2 in the postnatal establishment of the correct phenotype, layering and functions of this important cerebellar cell type.

\section{Materials and methods}

\section{Experimental animals}

Experiments were performed on different mouse lines: Sox2 flox (Favaro et al., 2009), Wnt1Cre (Danielian, Muccino, Rowitch, Michael, \& McMahon, 1998), GLASTCreErt2 (always used as heterozygous) (Buffo et al., 2008; Mori et al., 2006). Either sex was included. The day of vaginal plug detection was defined as embryonic day zero (E0) and the day of birth was considered as postnatal day zero (P0). Mice were maintained on a $12 \mathrm{hrs}$ day / night cycle with adequate food and water. All procedures were in accordance with the European Communities Council Directive (2010/63/EU and 86/609/EEC), the National Institutes of Health guidelines, and the Italian Law for Care and Use of Experimental Animals (DL26/14). 
They were approved by the Italian Ministry of Health and the Bioethical Committees of the Universities of Milan and Turin.

\section{Histological, in situ hybridization and immunohistochemical procedures}

In situ hybridization was performed as in (Favaro et al., 2009; A. Ferri et al., 2013). Briefly, embryos were fixed in 4\% paraformaldehyde (PFA) in $0.12 \mathrm{M}$ phosphate buffer (PB), pH7.27.4, cryoprotected, embedded in OCT and sectioned on a cryostat at $20 \mu \mathrm{M}$. Antisense probes for Sox2 (Avilion et al., 2003), Otx2 (Acampora, Avantaggiato, Tuorto, \& Simeone, 1997) and Gbx2 (Wassarman et al., 1997), a kind gift (Otx2; Gbx2) from Drs. L. Muzio and V. Broccoli, were in vitro transcribed in the presence of DIG-UTP and hybridized to sections at $65^{\circ} \mathrm{C}$. The signal was visualized by incubation with BM-purple (Sigma). For postnatal brain analysis, animals were transcardially perfused under anesthesia (hypothermia for pups up to postnatal day -P-7 and intraperitoneal injection of a mixture of ketamine $-100 \mathrm{mg} / \mathrm{kg}$; Ketavet, Bayern, Leverkusen, Germany- and xylazine $-5 \mathrm{mg} / \mathrm{kg}$; Rompun, Bayer, Milan, Italy- for older mice) with an appropriate volume of 4\% PFA in 0.12 M phosphate buffer (PB), pH7.2-7.4. Brains were removed, stored overnight $(\mathrm{o} / \mathrm{n})$ in the same fixative at $4{ }^{\circ} \mathrm{C}$, washed in Phosphate Buffered Saline (PBS) and finally cryoprotected in 30\% sucrose in $0.12 \mathrm{M}$ PB. The cerebella were then embedded and frozen over dry ice in OCT (TissueTEK), sectioned in the parasagittal plane at $30 \mu \mathrm{m}$ using a cryostat and collected in PBS (P30 juvenile and adult cerebella) or placed directly onto glass slides (E13-P7 cerebella). For immunolabelling, sections were incubated $\mathrm{o} / \mathrm{h}$ at room temperature with the appropriate primary antibodies dissolved in PBS with $1.5 \%$ donkey or goat serum (Jackson ImmunoResearch) and $0.25 \%$ Triton X-100 (Sigma-Aldrich): anti-S100BETA (S100B, 1:1000, mouse, monoclonal; Sigma), anti-glial fibrillary acidic protein (GFAP, 1:1500, rabbit, polyclonal; Dako), anti-brain lipid 
binding protein (BLBP, 1:500; rabbit, polyclonal; Abcam); anti-SOX2 (1:500, rabbit, polyclonal; Merck Millipore; 1:50, mouse, monoclonal, R\&D Systems); anti CALBINDIN(CALB, 1:1500, rabbit, monoclonal; Swant); anti-PARVALBUMIN (1:1500, mouse monoclonal; Swant); anti-myelin basic protein (MBP, 1:1000, mouse, monoclonal; BioLegend); anti-NG2 (1:250, rabbit, polyclonal; Merck Millipore); anti-Glutathione S-Transferase, Pi isoform (GSTPi, 1:500, rabbit, polyclonal; Eppendorf); anti-OLIG2 (1:500, rabbit, polyclonal; Merck Millipore). Sections were then exposed for $2 \mathrm{~h}$ at room temperature to secondary species-specific antibodies conjugated with Alexa Fluor 488, Alexa Fluor 555 or Alexa Fluor 647 (1:500; Invitrogen), or Cy3 (1:500; Jackson ImmunoResearch). Cell nuclei were visualized using 4',6diamidino-2-phenylindole (DAPI; Fluka). After processing, sections were mounted on microscope slides with Tris-glycerol supplemented with 10\% Mowiol (Calbiochem). Statystical detail on Immunofluorescence cell counting is in Supplementary Table 2 and Figure legends.

\section{Image processing and morphometric analyses}

Histological specimens were examined using an E-800 Nikon microscope connected to a color CCD camera or a Leica TCS SP5 confocal microscope. Adobe Photoshop 6.0 (Adobe Systems) was used to adjust image contrast and assemble the final images. On the basis of confocal images, ectopia, densities, lengths and distances were mapped and quantified by Neurolucida 7.0 (MBF Bioscience) or by NIH ImageJ (http://rsb.info.nih.gov/ij/)ssoftwares. Numbers of analysed animals for each time point or experimental condition are shown in the figure legends. Measurements were derived from at least three sections per animal. For evaluation of oligodendrocyte precursors and mature oligodendrocytes densities, cell counts 
were performed in two areas of lobules IV-V and IX, on confocal stacks of about $25 \mu \mathrm{m}$. Three sections per animal were examined.

The thickness (t) of the granular cell layer (GL) was determined on DAPI labelled slices according to the formula $t=2 \mathrm{~A} / \mathrm{b} 1+\mathrm{b} 2$, as in Carulli et al (2002). "A" was given by the area defined by the outer and inner profile of the granular layer, and "b1" and "b2" were the lengths of the two profiles. At least three slices/animal and three animals/genotype were analyzed. Values were pooled to yield the final average thickness.

For morphometric measurements in adult mice, DAPI-stained sections next to the midline of the entire cerebellar vermis were analysed. The whole PCL length, the extension along the Rostro-Caudal (R-C) and Ventro-Dorsal (V-D) axes, the PCL length along each lobule and the extension of the fissures between lobules VIa-VIb and IXb-IXc were evaluated using a fluorescent microscope and traced by means of the Neurolucida software (MicroBrightfield). For the of R-C extension measurement, the points of maximal convexity of the crowns of lobules $\mathrm{V}$ and IXb were chosen as points of reference, whereas the length of the V-D axis was evaluated by measuring the distance from the invagination between lobules I and X (maximal concavity) and the midpoint in the crown of lobule VIb. The length of the PCL along each lobule was measured as the line connecting the midpoint of the basis of the two fissures preceding and following the folium of interest. The extension of the fissures was evaluated by measuring the length of PCL between the related inward indentation points. For evaluation of BG ectopia, BG densities and BG to PC ratios, cell counts were performed in three cortical areas of lobules III, IV-V and IX, on confocal Z stacks of about $15 \mu \mathrm{m}$. Three sections per animal were evaluated.

\section{Systemic administration of Tamoxifen}


To activate the Cre recombinase in GLASTCreERT2 Sox2 mice Tamoxifen (Tx) $(20 \mathrm{mg} / \mathrm{ml}$ solution dissolved in corn oil) was administered via subcutaneous injection for pups (20 $\mathrm{\mu g} / \mathrm{g}$ body weight) or via oral gavage for adults ( $5 \mathrm{mg} / 40 \mathrm{~g}$ body weight). Mice were given either a single Tx injection at P2 or administered a double treatment including a first single injection at P8 and a further treatment at P60. A distinct cohort of adult mice was treated at 4 months of age to assess the effects of Sox2 deletion after the completion of cerebellar maturation. However, at 2 months after treatment no changes in BG layering were observed, suggesting that Sox2 is dispensable to preserve BG morphology and layering at adult stages, when cerebellum maturation is fully accomplished. As for experiments performed in Wnt1-Cre Sox2 mice, animals with mixed genotypes were used as controls (Sox2F/+;CreERT2, Sox2FF or Sox2F/+) for some analyses. In other instances, Sox2F/F;CreERT2 mice with no Tx treatment were also employed as controls, as indicated in Supplementary Table 1.

\section{Behavioural Assays}

All behavioral experiments were conducted in a dedicated dimly illuminated $(2 \times 40 \mathrm{~W}$ indirect) testing room during the standard light phase, usually between 9:00 AM and 2:00 PM (rotarod from 10:00 AM to 12:00 AM, beam test from 10:00 AM to 1:00 PM, open field from 10:00 AM to 2:00 PM). In all tests, the cages containing mice were moved into the testing room 1 hour before the first trial began. For Wnt1-Cre Sox2 mutants of either sexes were examined and pooled together, as no difference was appreciated between genders. For GLASTCreERT2 Sox2 mutants, in cases of relevant differences data for males and females are presented separately. 
Rotarod test. Motor coordination, balance and motor learning were assessed using an accelerating rotarod (Ugo Basile, Varese, Italy; (Fuca et al., 2017)). The rotarod apparatus had five flanges dividing the five $5.7 \mathrm{~cm}$ lanes, the cylinder diameter was $3.5 \mathrm{~cm}$. Mice were placed on the rotating bar and given a habituation period of $2 \mathrm{~min}$ at constant velocity (5.5 rpm), after which the rotating bar accelerated from 5.5 to 60 rpm over 300 seconds. Mice were put on the rotarod until the latency to fall off reached the total time of $300 \mathrm{~s}$. Three trials per day with 3-5 min intervals, on three consecutive days were performed; we considered the averages of the three sessions. During pauses between trials, mice rested in their home cages

Beam walking test. In order to assess balance capabilities, beam walking test has been used (adapted from (Hilber \& Caston, 2001)). Testing was performed once for month for mice of each group. The apparatus consisted of a motionless wooden beam with a rectangular section $(1 \mathrm{~cm} \times 3 \mathrm{~cm}), 1 \mathrm{~m}$ in length, placed $80 \mathrm{~cm}$ above a foam carpet. At the onset of the single trial, each animal was placed at one extremity of the beam, its body axis being perpendicular to the beam long axis. We recorded the time spent to complete each cross and the number of paw faults or slips made during the passages to the wooden bar, for a final number of 5 crossings of the bar. Then, for each animal, the frequency of slip and the time spent to cross the beamwere calculated. After 5 consecutive, unsuccessful trials to stay on the bar, the test was considered failed.

Open field. Animals were tested in a forex arena $(50 \times 50 \mathrm{~cm})$, which was divided into a central (25 x $25 \mathrm{~cm}$ ) and a peripheral zone (Cupolillo et al., 2016). The animal was placed in the corner of the open field and was allowed to explore the arena for $10 \mathrm{~min}$. Distance 
travelled and time spent in the central zone was recorded and analyzed by Ethovision XT video track system (Noldus Information Technology, Wageningen, Netherlands).

\section{Electrophysiology}

The animals were anesthetized with isoflurane (Isoflurane-Vet, Merial, Italy) and decapitated. The cerebellar vermis was removed and transferred to an ice-cold artificial cerebrospinal fluid (ACSF) containing (in mM); $125 \mathrm{NaCl}, 2.5 \mathrm{KCl}, 2 \mathrm{CaCl}$, $1 \mathrm{MgCl} 2,1.25 \mathrm{NaH} 2 \mathrm{PO} 4,26$ NaHCO3, 20 glucose, which was bubbled with 95\% 02/5\% CO2 (pH 7.4). Parasagittal cerebellar slices (200 $\mu \mathrm{m}$ thickness) were obtained using a vibratome (Leica Microsystems $\mathrm{GmbH}$, Wetzlar, Germany) and kept for $1 \mathrm{~h}$ at $35^{\circ} \mathrm{C}$ and then at $25^{\circ} \mathrm{C}$. Single slices were placed in the recording chamber, which was perfused at a rate of $2-3 \mathrm{ml} / \mathrm{min}$ with ACSF bubbled with the $95 \% 02 / 5 \% \mathrm{CO} 2$. All recordings were performed at room temperature $\left(22-25^{\circ} \mathrm{C}\right)$. The data derive from 5 to 7 animals.

Whole-cell patch-clamp recordings were made from PCs of adult animals of both genotypes using an EPC-9 patch-clamp amplifier (HEKA Elektronik, Lambrecht/Pfalz, Germany). We performed recordings in the posterior lobules of cerebellum. Pipettes of borosilicate glass with resistances between 2.5 and $3.0 \mathrm{M} \Omega$ were used. Patch pipettes were filled with an internal solution containing (in $\mathrm{mM}$ ): $130 \mathrm{CsCl}, 4 \mathrm{MgCl}_{2}, 10$ HEPES, $4 \mathrm{Na}_{2} \mathrm{ATP}, 0.4 \mathrm{Na} 3 \mathrm{GTP}, 10$ EGTA, 5 N-(2,6-dimethylphenyl)acetamide-2-triethylammonium bromide (QX-314) and the pH was adjusted to 7.3 with $\mathrm{CsOH}$ and filtered at $0.2 \mu \mathrm{m}$. $\mathrm{Cs}^{+}$blocks most outward currents through $\mathrm{K}^{+}$channels while QX-314 blocks voltage-gated $\mathrm{Na}^{+}$channels. Recordings were accepted only if the series resistance was less than 9.0 $\mathrm{M} \Omega$ (range: 5.0-9.0 $\mathrm{M} \Omega$ ), and if it did not vary by $>20 \%$ during the experiment. Data were filtered at $3 \mathrm{kHz}$ and sampled at $10 \mathrm{kHz}$. 
For all the experiments, digitized data were stored on a personal computer using the Patch Master software (HEKA Elektronik, Lambrecht/Pfalz, Germany) and analized off-line.

PF-EPSCs were evoked by stimulating the PFs in the molecular layer while the PC was kept at a holding potential of $-90 \mathrm{mV}$. The stimulation was done with a glass pipette, pulled from sodalime glass to a tip diameter of $10-15 \mu \mathrm{m}$, containing the saline solution. Negative current pulses ranging from 3 to $15 \mu \mathrm{A}$ with a duration of 100 ? $\mu$ s were delivered at 20 s intervals. Paired pulse facilitation was elicited by applying double pulses of $9 \mu \mathrm{A}$ of intensity at different time intervals $(50,100,150,200 \mathrm{~ms})$, and the ratio of the amplitude of the second PF-EPSC over the first one was calculated. All PF recordings were performed in the presence of gabazine (SR 95531, $20 \mu \mathrm{M}$ ) in the saline solution.

\section{Gliosome purification}

Animals were euthanized and the whole brain rapidly removed. The cerebellar cortex was dissected on ice at $4^{\circ} \mathrm{C}$; care was taken to dissect away the white matter, containing fibrous (parenchymal) astrocytes, as much as possible, to obtain an astrocyte preparation highly enriched in BG; glial perisynaptic processes (gliosomes) were then prepared from control and Sox2F/F; Wnt1Cre mutant mice essentially as previously described (Milanese et al., 2010; Raiteri et al., 2008), with minor changes. Briefly, the tissue was homogenized in $0.32 \mathrm{M}$ sucrose, buffered at pH 7.4 with Tris- $\mathrm{HCl}$, using a glass-teflon tissue grinder (clearance $0.25 \mathrm{~mm}$ - Potter-Elvehjem VWR International). The homogenate was centrifuged ( $5 \mathrm{~min}, 1,000 \mathrm{xg}$ ) to remove nuclei and debris, the supernatant centrifuged at $12,000 \times \mathrm{g}$ for $10 \mathrm{~min}$ and the pellet resuspended in Tris-buffered 0.32 M sucrose and gently layered on a discontinuous Percoll ${ }^{\circledR}$ (Sigma-Aldrich, St Louis, Missouri, USA) gradient (2, 6, 10 and 20\% v/v in Tris-buffered 0.32 M sucrose). After centrifugation at 33,500 $\mathrm{g}$ f for $5 \mathrm{~min}$, the layer between 2 and 6\% Percoll ${ }^{\circledR}$ (gliosomal 
fraction) was collected and washed by centrifugation at 20,000xg for 15 min with physiological medium (PM) having the following composition (mM): $\mathrm{NaCl}, 140 ; \mathrm{KCl}, 3 ; \mathrm{MgSO}_{4}$, 1.2; $\mathrm{NaH}_{2} \mathrm{PO}_{4}, 1.2 ; \mathrm{NaHCO}_{3}, 5 ; \mathrm{CaCl}_{2}, 1.2 ; 4$-(2-hydroxyethyl)-1-piperazineethanesulfonic acid (HEPES), 10; glucose, 10; pH 7.4. Gliosomes were re-suspended in PM for uptake experiments or lysed in Ultrapure water (Milli-Q; Millipore, Billerica, MA, USA) for endogenous glutamate/glutamine determination. All the above procedures were conducted at $4^{\circ} \mathrm{C}$. Protein content was measured according to (Bradford, 1976) using bovine serum albumin (SigmaAldrich, St Louis, Missouri, USA) as a standard.

\section{Uptake experiments}

Uptake was measured in gliosomes purified from BG-enriched glia of control (Sox2FF/F+) and mutant (Sox2F/F;Cre) mice as previously described (Milanese et al., 2015). Briefly, gliosomes

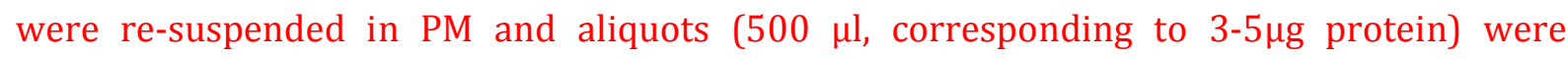
incubated for $5 \mathrm{~min}$ at $37{ }^{\circ} \mathrm{C}$ and the $20 \mu \mathrm{l}$ of a solution of [ $\left.{ }^{3} \mathrm{H}\right] \mathrm{D}$-Aspartate $\left(\left[{ }^{3} \mathrm{H}\right] \mathrm{D}\right.$-Asp)(specific activity: $16.5 \mathrm{Ci} / \mathrm{mmol}$, Perkin Elmer Italia, Milan, Italy), a non-metabolizable analogue of glutamate (Glu), used to mimic the endogenous neurotransmitter as a substrate of Glu transporters (Raiteri et al., 2007) was used, to obtain the final concentrations of $0.3,3,5,30$, and $100 \mu \mathrm{M}$. After 2 min incubation at $37^{\circ} \mathrm{C},\left[{ }^{3} \mathrm{H}\right] \mathrm{D}$-Asp uptake was blocked by rapid vacuum filtration on glass fiber filters (GF-B, Millipore, Billerica, MA, USA) and washed three times with $5 \mathrm{ml}$ of standard medium to remove the excess of radioactivity. Aliquots of gliosomes were exposed to the same concentrations of $\left[{ }^{3} \mathrm{H}\right] \mathrm{D}$-Asp at $0-4{ }^{\circ} \mathrm{C}$ in the presence of $50 \mu \mathrm{M}$ of the broad spectrum Glu uptake inhibitor $D L$-threo-beta-benzyloxyaspartate (DL-TBOA; Tocris Bioscience, Bristol, UK; Shimamoto et al., 1998) to detect the non-specific binding to the gliosomal membranes. Radioactivity was determined by liquid scintillation counting. The 
specific uptake was calculated by subtracting non-specific binding from the total uptake. To calculate the kinetic parameters Vmax and Km for the two experimental groups, data were fitted by the Michaelis-Menten equation $\mathrm{V}=\mathrm{Vmax} * \mathrm{~S}] / \mathrm{Km}+[\mathrm{S}]$, using the SigmaPlot 10.0 and SigmaStat fitting setup (Systat Software, Inc., San Jose, CA, USA).

\section{Endogenous glutamate and glutamine determination}

BG cells gliosomes from control (Sox2FF/F+) and mutant (Sox2F/F;Cre) mice were lysed in hypotonic ultrapure water, and the cytosolic extracts separated from membrane debris by centrifugation (10 min 20,000xg). The endogenous glutamate and glutamine content were quantified in supernatants by previously described high performance liquid chromatography analysis (Milanese et al., 2011). The methods consisted in a pre-column derivatization of the samples with o-phthalaldehyde, followed by discontinuous gradient separation using a C18 reverse-phase chromatographic column (Agilent MicroSpher C18, S100x4.6, $3 \mu \mathrm{m}$; CPS Analitica, Milano, Italy) at $30^{\circ} \mathrm{C}$, and fluorometric detection (excitation wavelength $350 \mathrm{~nm}$; emission wavelength $450 \mathrm{~nm}$;). Homoserine (Sigma-Aldrich, St. Louis, MO, USA) was used as an internal standard.

\section{Statistical analyses}

Data elaboration and statistical analyses were conducted by means of GraphPad software Prism version 7.0 (GraphPad software, San Diego; SPSS,IBM) In all instances, ${ }^{*} \mathrm{P}<0.05$ was considered as statistically significant, ${ }^{* *} \mathrm{P}<0.01$ very significant and ${ }^{* * *} \mathrm{P}<0.001$ extremely significant. Graphs and data are represented as means \pm standard errors. If data sets passed normality test and equal variance test, we performed Student's t-test or One/Two Way Anova 
followed by Bonferroni post hoc tests. When data did not satisfy the normality or equal variance tests, corresponding non-parametric statistics was used. To compare different percentages, we transformed the values in radiants according to the arcsin transformation. Cumulative frequency plots were analyzed by Kolmogorov-Smirnov (KS) test. The graphs of electrophysiology results were designed using Igor Pro (WaveMetrics, Lake Oswego, Oregon, USA). Details about statistical assessment and numerical values obtained are provided in Supplementary Tables 1 and 2.

\section{RNAseq from wild type and mutant neural stem cell-derived in vitro differentiated cells}

Neurosphere cultures were derived from wild type and Sox2-mutant mouse forebrain cells. Sox2 ablation was obtained at E11.5 by Nestin-Cre deletion; at P0, neural stem cells populations from three wild type and three Sox2 mutant forebrains, were individually placed in culture (in the presence of EGF and FGF) to generate neurospheres (as in Favaro et al. 2009). For differentiation, neurospheres from the individual cultures were dissociated to single cells, and plated onto MATRIGEL (Becton-Dickinson)-coated tissue culture dishes at 1,5 x $10^{6}$ cells $/ 10 \mathrm{~cm}$ dish (Gritti et al., 1996; Zappone et al., 2000), with bFGF only as mitogen. After 4 days, the medium was changed to neural stem cell medium without bFGF, and supplemented with $1 \%$ fetal calf serum (FCS). At day eleven, cells were collected for RNA analysis (at this stage, over $90 \%$ of the cells are glial cells in wild type cells, and about $95 \%$ in mutant cells). RNA extraction was performed on the three independent NSC populations for both wild type and mutant cells, using Trizol and RNeasy Kit (Qiagen). 1/5 volume of chloroform was added to one volume of Trizol. The aqueous phase was transferred into a new tube. $1.5 \mathrm{x}$ volume of ethanol was added and thoroughly mixed. The mixture was filtered through Rneasy (Qiagen) columns; the columns were washed with Buffer RW1. On-column 
DNase treatment was performed as described by the RNase-Free DNase Kit (Qiagen). Post treatment columns were cleaned up with Buffer RW1 and two washes of RPE buffer. Columns were then dried and total RNA was eluted with RNase-free water. PolyA Stranded Truseq Libraries were generated using the Truseq Stranded mRNA Sample Preparation Kit (Illumina). First, mRNA was purified from $1 \mu \mathrm{g}$ of total RNA using magnetic beads containing poly-T oligos. mRNA was then fragmented and reverse transcribed using Superscript II (Invitrogen), followed by second strand synthesis. Double stranded cDNA was treated with end-pair, A-tailing, adapter ligation and 8 cycles of PCR amplification.

RNA-Seq was performed on all individual samples (three wild type and three mutant) studied, to yield single-end reads. The number of sequences obtained in each sample ranged from 7.5 to 12.5 millions.

Read counts and transcript levels for each sample were computed with the RSEM software package version 1.17 (B. Li \& Dewey, 2011), on the RefSeq gene annotation available at the UCSC Genome Browser for mouse genome assembly mm9 (24,148 genes). For downstream analyses, expression levels measured as Transcripts per Million (TPM) were employed. Differential expression analysis was performed with the NOISeqR package (Tarazona et al., 2015). Differentially expressed genes were selected by employing a q-value threshold of 0.99, corresponding to an empirical false discovery rate (FDR) of 0.01 .

\section{Results}

\section{Conditional Sox2 mutants develop ataxia}


To address the consequences of Sox2 loss in the developing cerebellum, we used mice carrying a Sox2flox conditional knockout (cKO) allele, previously generated in our laboratory (Favaro et al., 2009); to delete Sox2, we used Wnt1-Cre, active from embryonic day 9.5 (E 9.5) in the developing midbrain-hindbrain region, where the cerebellum will arise (Danielian et al., 1998). In situ hybridization at E9.5 in wild type embryos shows Sox2 mRNA expression in the neuroepithelium (consisting, at this stage, of undifferentiated progenitors of neurons and glia), throughout the developing neural tube, including the midbrain-hindbrain region where the cerebellum will arise; in the mutant, Sox2 mRNA was lost in the developing mesencephalon and anterior rhomboencephalon by E9.5 (Fig. 1a).

Wnt1-Cre Sox2 mutant mice (Sox2F/F;Cre hereafter) are born in normal mendelian ratios; most survive to adulthood, though a few are lost before weaning (when mutants represent $20 \%$ of the offspring, instead of the expected $25 \%$ ).

We initially observed clear motor abnormalities in a number of adult mutant mice, suggesting possible cerebellar defects. To precisely address functional cerebellar abnormalities in Sox2 mutants, we subjected them to behavioural tests of motor coordination and equilibrium, used to detect alterations that arise following cerebellar damage: the rotarod and balance beam tests (Fuca et al., 2017; Hilber \& Caston, 2001). We compared motor performances of mutants and control littermates between 1 and 8 months of life (Fig. 1b-d). By the rotarod test, latency to fall (whose shortening is indicative of motor control damage) was significantly shorter from 2 months of age (Fig. 1b). Heterozygous (Sox2F/+;Cre) mice also showed a moderately reduced latency, though the defect was less pronounced than that of homozygous mutants (Fig. 1b). The beam-walking test revealed a significant impairment of the Sox2F/F;Cre mutants as compared to controls, not only in the execution of the test, with a significantly higher number of slips (Fig. 1c), but also in the time needed to complete the crossings on the 
beam bar, especially at the earliest time points (Fig. 1d). Thus, Sox2 deletion during cerebellar development leads to defects in fine motor coordination and balance.

\section{Wnt1-Cre-mediated Sox2 deletion leads to morphological cerebellar abnormalities}

To understand the causes of the observed ataxic defects, we studied the mutant cerebellum during development and postnatally. Sox2 deletion at E9.5 via Wnt1-Cre results in early posterior shifts of the expression boundaries of two genes, Otx2 and Gbx2, and an early thinning of the neuroepithelium in the medial, prospective vermis region (Supporting Information Fig. S1). Otx2 and Gbx2 encode transcription factors required for the precise spatial definition of the isthmic organizer, a signalling center marking the boundary between prospective mesencephalon and cerebellum, and for subsequent vermis development (Joyner, Liu, \& Millet, 2000; J. Y. Li, Lao, \& Joyner, 2002; Martinez, Andreu, Mecklenburg, \& Echevarria, 2013; V. Y. Wang \& Zoghbi, 2001); the correct relative positioning of Otx2 and Gbx2 expression territories is critical for the appropriate development of the isthmic organizer (Broccoli, Boncinelli, \& Wurst, 1999).

At birth, abnormalities of cerebellar morphology were observed (Fig. 1e, showing postnatal day 5, P5). The most prominent defects were seen in the medial region, the vermis, which was underdeveloped, in particular along its antero-posterior axis (Fig. 1e,f). Different degrees of severity were observed: from severe reduction (Fig. 1e, far right; "severe" mutants, 11\% of total) to milder (though visible) effects, in all other mutants (Fig. 1e left; "moderate" phenotype).

We addressed cerebellar vermis morphology in more detail in three adult mutants (8 months, moderate phenotype), by morphometric analyses (Fig. 2). Vermis alterations were observed in all three mutants: measurements of the total length of the Purkinje cell layer (PCL), and of 
the rostro-caudal vermian axis, revealed a reduction in size, with no changes in the thickness of the granule layer (GL) (Fig. 2e-h). Consistent with this result, also PCL lengths in various specific lobules were shorter compared to controls; this reduction was most prominent in lobules IV/V, VIb, and IX and X (20-60\% reduction; these lobules are particularly important for equilibrium and posture) (Fig 2i-k). More subtle alterations in foliation were also detected; indeed, the late-born secondary fissure separating lobule IXb/IXc was not observed in mutants, and the VIa/VIb fissure showed a trend to decrease in length (Fig. 2a,b,c,l,m).

\section{Sox2 mutants show alterations of Bergmann glia monolayer formation arising postnatally}

To further investigate possible mechanisms for the mutant phenotype, we looked for abnormalities at the cellular level within the postnatal cerebellum, where neurons and glia complete their terminal differentiation and acquire their function.

We first looked at Sox2 expression in the wild type postnatal cerebellum, by double immunofluorescence for SOX2 and cell-type-specific antibodies. At early postnatal ages, SOX2 was clearly expressed in S100B-positive BG (Fig. 3a-b"), though apparently not in adjacent, CALBINDIN-positive PCs (Fig. 3c-c'”), in agreement with previous reports (Shiwaku et al., 2010; Sottile, Li, \& Scotting, 2006). SOX2 was also expressed by parenchymal astrocytes of the GL and prospective white matter (PWM; Fig. 3a-b), as expected (Sutter et al., 2010). The same pattern of expression was maintained in adult cerebella at 8 months of age (Fig. $\left.3 \mathrm{~d}-\mathrm{d}^{\prime \prime \prime}\right)$. In Sox2F/F; Cre mutant mice, Sox2 was not detected, as expected (Fig. 3e-f').

We then looked at possible alterations, in mutants, within specific postnatal cell types, by immunofluorescence with cell type-specific markers, at P7, P19 and 8 months. At 8 months, we did not detect major changes in the density, nor morphology, of PCs, nor of interneurons 
(by CALBINDIN and PARVALBUMIN immunofluorescence, respectively) in mutants compared to controls (Supporting Information Fig. S2). As Sox2 is expressed in oligodendrocyte progenitors during development (Zhao et al., 2015), we also examined oligodendrocytes by immunofluorescence using anti-NG2 (recognizing immature oligodendrocyte progenitors), GSTPi (post-mitotic differentiating oligodendrocytes) and Olig2 (the entire oligodendrocyte lineage): no significant differences in the density or distribution of labelled cells was observed at 10 weeks of age (Supporting Information Fig. S3a-c'”). In addition, overall myelination, as detected by MBP immunofluorescence, was not altered in mutant as compared to control mice (Supporting Information Fig. S3d-e"). We then investigated glial cells, which have essential roles in the maintenance of cerebellar neuronal function. In particular, BG cells, which express Sox2 (Fig. 3), surround with their cell bodies the PC, enwrap their cell dendrites, and are critical for their function (Buffo \& Rossi, 2013; Custer et al., 2006; Miyazaki et al., 2017). We performed immunofluorescence with antibodies against BLBP (recognizing BG progenitors at P7), and S100B and GFAP (recognizing fully differentiated glia cells, in particular BG, at later stages) (Fig. 4a-r). At P7, mutant cerebella did not reveal overt differences in BLBP- or S100Bpositive glial cell number, morphology, or localization, when compared to the two control genotypes (Sox2F/F, Sox2F/+, or Sox2F/+; Cre ; 'controls')(Fig. 4, compare m-o, mutant, with a-c and g-I , controls). At P19, however, abundant S100B/GFAP-positive cell bodies suggestive of mislocalized BG cells were observed in the molecular layer (ML) of the mutant, (Fig. 4p-p"), in contrast with the orderly alignment of S100BETA/GFAP-positive cell bodies along the PCL, with parallel radial projections extending across the ML, observed in controls (Fig. 4d-d", j-j"). GFAP immunofluorescence (staining the cytoplasm more intensely than S100B) further showed that ectopic cells had a non-radial, abnormal morphology (Fig. 4p", arrowheads). These ectopic cells were still abundant at 8 months (Fig. 4, compare q-r, mutant, to e-f and k-l, 
controls; quantitation in s), and GFAP immunofluorescence highlighted a characteristic aberrant, multipolar morphology, with dense arborizations (Fig. 4r, arrowheads). The abnormal cell morphology was particularly evident in the ectopic cells (Fig. 4r', inset), but also occasionally observed on the cells aligned along the PCL (Fig. 4r, arrows). Overall, the number of non-ectopic BG in the mutant PCL was significantly decreased compared to control animals (Fig. 4t,u). Importantly, by contrast with the abnormalities in mutant BG, parenchymal astrocytes of the GL and WM appeared unchanged among genotypes (Supporting Information Fig. S2). We conclude that the localization and morphology of glial cells (BG, based on the location) are progressively altered during postnatal life in Wnt1Cre-Sox2 mutant mice.

\section{Alteration of synaptic transmission at parallel fiber-Purkinje cell synapse}

Given the important role of BG in modulating the excitatory synapse transmission in PCs, we examined synaptic transmission between parallel fibers (PFs) and PCs by means of whole-cell voltage clamp. We performed our analysis in adult mice, in the posterior lobules of the cerebellum, which had revealed the most prominent reduction of the PCL length (Fig. 2). We electrically stimulated PFs using a stimulation electrode placed in the molecular layer and recorded excitatory glutamatergic synaptic currents (PF-EPSCs) in the PC. PF-EPSCs had comparable amplitudes at every intensity of stimulation in both mutant ( $\mathrm{n}=16$ cells) and control mice ( $\mathrm{n}=17$ cells) ( $\mathrm{P}>0.05$, Two- way ANOVA repeated measures -RM-) (Fig 5a-b). However, while most EPSCs of control mice had amplitudes smaller than 250 pA with stimulus strength of $12 \mu \mathrm{A}$ (Fig 5c), a large fraction of mutant mice EPSCs exceeded this value (Fig 5d). Cumulative plots revealed significant differences between genotypes in the distribution of EPSC amplitudes, with mutant values shifted to the right towards larger values $(\mathrm{KS}, \mathrm{P}<0.0001$ ) (Fig 5e). To evaluate possible alterations in glutamate release from 
presynaptic terminals we stimulated PFs with paired stimuli at different intervals. The analysis of paired pulse facilitation of the PF-PC synapse did not show differences between genotypes, suggesting a preserved presynaptic release of glutamate by $\mathrm{PFs}(\mathrm{P}>0.05$, Two way Anova RM) (Fig 5f-g). Alterations of BG are associated with changes in the kinetics of PFEPSCs (Takayasu et al., 2005). To address this issue we measured the decay time constant of PF-EPCSs. We did not find changes between genotypes in the decay time constant (for controls: $19.26 \pm 1.45 \mathrm{~ms}$; for mutant mice: $18.36 \pm 2.25 \mathrm{~ms}$ P $>0.05$, Student's t-test). However, the analysis of the distribution of decay time constants of mutant mice EPSCs revealed the presence of two populations with faster and slower decays (data not shown), while the data of control mice were better described as a single population. The heterogeneity of the synaptic properties of the EPSCs is in line with the presence of ectopic BG, which might alter synaptic transmission at nearby synaptic contacts.

Sox2 postnatal deletion in radial glia leads to ectopic, abnormal and disorganized Bergmann glia and to mild motor control defects

The expression of SOX2 in postnatal BG, together with the defects in BG observed in mutants, raised the possibility that SOX2 could be required postnatally, within the BG itself, to maintain these cells and their characteristics. To test this hypothesis, we deleted Sox2 in BG postnatally, by means of a tamoxifen (Tx)-inducible Cre encoded by a GLASTCreERT2 transgene (Buffo et al., 2008; Mori et al., 2006). Tx was administered at P2 or P8, and cerebella were analysed at 1 or 8 months of age (Fig. 6). Cre induction leads to efficient ablation of SOX2 from S100B-positive BG, reaching 60-80\% (Fig. 6c-d, mutant, compare to a-b, controls; quantitation in e). In controls, at P30, the S100B-positive BG (red), largely Sox2-positive (green), form an ordered array of cells with their cell bodies aligned in the PCL (at the bottom 
of the molecular layer)(Fig. 6a-a",b-b"); by contrast, in the mutant, S100B-positive cells show wide disorganization, with their cell bodies localized throughout the molecular layer (Fig. 6c$c^{\prime \prime}, d-d "$, quantitation in f). Sox2 immunofluorescence confirms absence of SOX2 from most S100B-positive cells in the mutant (Fig. 6c-c",d-d"), to be compared to the wide Sox2positivity of S100B-positive cells in the control (Fig. 6a-a",b-b"). S100B/GFAP immunofluorescence at 8 months confirmed that S100B-positive cells in mutant were widely disorganized and mislocalized, and showed highly abnormal morphology by GFAP immunostaining, together with a disruption of the normal, radial organization of the BG, and abundant ectopic BG (Fig. 6g-i, compare h, mutant, to g, control). Similar to what found in Wnt1Cre Sox 2 mutants, deletion of Sox 2 also leads to a decreased amount of BG in the PCL, as indicated by a similar reduced BG/PC ratio in both mutant lines (Sox2F/F;CreERT2, 2.939 \pm 0.098 vs Sox2F/F;Cre 2.606 \pm 0.1487 ) compared to controls (not shown).

These findings indicate that Sox2 is required during postnatal life to maintain BG alignment along PC cell bodies, and their characteristic radial morphology and organization.

We further asked if postnatal Sox2 deletion would lead to motor control defects, together with BG abnormalities. Since Tx injection in P2 animal significantly affected newborn survival and for behavioural studies numerous litters are needed, we postponed the treatment to P8 and combined it with a second administration at P60 (see Materials \& Method section). This protocol determined BG ectopia to an extent similar to Tx treatment at P2 (Fig. 6i). By the beam-walking test, a significant difference was found between mutants and controls, with no differences between sexes (not shown), similarly to what observed with Wnt1-Cre mutants, although the extent of the motor alterations was much smaller (Fig. 7a,b). By the rotarod test, mutants did not perform significantly different from controls (Fig. 7c). However, when male 
and female mutant and control mice were separately compared, mutant male mice, that initially performed comparably to controls (month 1), later (month 2) showed a significantly worse performance than controls, though the difference was clearly smaller than that found for Wnt1-Cre mutants (see Fig. 1b-d)(Fig. 7d). We wished to check if the abnormalities detected in the motor control tests (small, though statistically significant) could be affected by an increased anxiety in the mutants influencing motor performances. We thus performed, on the same mice previously evaluated in the motor control tests, a test evaluating both anxiety and general locomotor activity, the Open field test. No significant difference was observed between mutants and controls. (Fig. 7d). We conclude that postnatal Sox2 deletion in glia leads to mild motor control defects, based on both the beam-walking and rotarod tests.

\section{Abnormalities of glutamate transport in Sox2 mutant BG}

BG expresses the excitatory amino acid - glutamate transporter GLAST (encoded by the Slc1a3 gene), important for the removal of glutamate from the synaptic cleft, and mutations in human SLC1A3 were found in patients affected by episodic ataxia (Jayadev \& Bird, 2013). Further, BG was shown to be essential for synaptic organization and electrophysiological function of PCs through the action of GLAST, in studies of Slc1a3 knockout mice (Miyazaki et al., 2017). Glutamatergic transmission requires the involvement of glia cells to efficiently clear the synaptic cleft and to recycle the transmitter through a Glutamate to Glutamine (Glu/Gln) metabolic shuttle, in a multicomponent regulated process. We thus performed Glu uptake experiments in gliosomes purified from BG-enriched cell preparations of 6 wild type and 5 Sox2-Wnt1Cre mutant mice. Gliosomes represent a well-recognised subcellular preparation that recapitulates molecular and functional features of the astroglial perisynaptic processes (Carney et al., 2014; Stigliani et al., 2006). As shown in Fig. 8, Sox2-Wnt1Cre gliosomes 
showed a significant increase of uptake Vmax, compared to age matched control mice, with no significant changes in the Km values (Supporting Information Figure S4). In parallel we measured the gliosomal content of endogenous Glu and Gln, and calculated the Glu/Gln ratio: these ratios were statistically comparable in gliosomes from Sox2-Wnt1Cre and WT BG mice (Supporting Information Figure S4). These data demonstrate a clear biochemical alteration of the Sox2-mutant BG cells, namely, Glu uptake abnormalities, without modification of Glu/glutamine conversion.

Sox2 deletion in neural stem cells causes widespread deregulation of gene expression in in-vitroderived glial cells

Previous work (Koirala \& Corfas, 2010) identified genes expressed in BG at P6, or P30, or at both stages. To gain insight into the effect of Sox2 deletion on gene expression in glia, we differentiated in vitro neural stem cells obtained, at P0, both from wild type newborn mice and from littermates embryonically deleted for Sox2 (at E11.5, see (Favaro et al., 2009)). We then determined genes deregulated at day 11 of in vitro differentiation; at this stage, cells are postmitotic, and $90-95 \%$ of them are glial cells, with a small proportion of oligodendroglia (12\%) and neurons (about 5\%). Finally, we compared the list of deregulated genes in differentiated mutant glia with those of genes expressed in BG at P6, P30, or both. Over 450 genes, out of 1183 genes expressed at both P6 and P30 in BG, were found to be deregulated in Sox2-mutant glia (Supplementary Table 3); furthermore, a highly significant fraction (266 genes) is likely to be direct SOX2 targets, based on published SOX2 ChIP-seq data (Lodato et al., 2013) in which SOX2 target genes were defined as being SOX2-bound in regulatory regions (Supplementary Table 3). These results point to an important role of Sox2 in the control of gene expression in differentiated glia, and possibly BG. Interestingly, among SOX2-bound, BG- 
expressed genes downregulated in Sox2-mutant cells (SOX2_UP WT_UP BOTH in Supplementary Table 3), several (highlighted) are potentially related to ataxia, based on previous publications. Among these genes, Slc1a3 (GLAST) was Sox2-bound and moderately reduced, at statistically significant values, in in vitro differentiated glia, implying a potential effect of Sox2 deficiency on glutamate uptake; however, Slc1a3 expression, as detected by immunofluorescence in BG in tissue sections, was somewhat variable between different mutant mice, and overall not significantly different from controls (not shown). On the other hand, glutamate uptake by BG is a complex phenomenon, affected by many different components (i.e. gene products) in addition to the Slc1a3 protein amount. Future work will better define the relations between the altered gene expression pattern caused by Sox 2 deficiency and the increased glutamate uptake that we detected in mutant BG, as well as their relation with PC dysfunction and ataxia.

\section{Discussion}

Sox2 mutations in man cause genetically dominant defects in the central nervous system, including hippocampus hypoplasia, cognitive defects, motor control abnormalities, seizures, retina and eye defects; some of these abnormalities have been reproduced in mouse models of conditional Sox2 ablation (Dennert et al., 2017; Favaro et al., 2009; A. Ferri et al., 2013; Pevny \& Nicolis, 2010; Ragge et al., 2005; Sisodiya et al., 2006). In previously studied Sox2 mutant mouse models, the observed defects develop prenatally, or immediately after birth, and are related mainly to neural stem/progenitor cells defects. An exception is represented by abnormalities of GABAergic interneurons morphology and postmitotic migration (Cavallaro et al., 2008) in the forebrain, as well as defects of differentiated glia types: Mueller glia, a 
differentiated glial type of the eye, and oligodendroglia (Bachleda, Pevny, \& Weiss, 2016; Hoffmann et al., 2014; Pevny \& Nicolis, 2010).

In our Wnt1Cre-Sox2flox mouse model, we report that Sox2 is important for the correct prenatal morphogenesis of the cerebellum, and in particular of the vermis. In addition, Sox2 controls the correct morphology, organization/localization and development of the BG in the first three weeks after birth. As the BG population is mainly postmitotic after the first postnatal week, when BG defects arise, this finding points to important roles of Sox2 within a specifically differentiating, non-dividing, glia cell type.

The cerebellar defects we observed lead to ataxic features, which are more pronounced when Sox2 deletion is performed prenatally, but are still observed with (partial) postnatal deletion within BG.

\section{Genetic mechanisms contributing to the development of ataxic features}

The significant reduction of the vermis observed in newborn Wnt1Cre Sox2 mutants is one plausible contributor to the ataxic features appearing shortly after birth. In fact, vermis reduction, together with ataxia, was previously observed, in several mutant mouse models and human inherited diseases. In mouse, an experimental posterior shift (by Otx2 knock-in into the En1 locus) of the caudal expression boundary of the Otx2 transcription factor, a critical regulator of the cerebellum/mesencephalon boundary, leads to impaired vermis development and to ataxia (Broccoli et al., 1999). Our Sox2 mutant mimics, to a certain extent, the expression changes of Otx2 (and of Gbx2) observed in this mutant mouse model (see Supporting Information Fig. 1), suggesting that vermis reduction in the Sox 2 mutant is due, at least in part, to $0 t x 2 / G b x 2$ dysregulation. In humans, vermis reduction is observed, together with ataxia, in CHARGE syndrome, an autosomal dominant disorder caused by mutation of 
CHD7 (Yu et al., 2013), a chromatin regulatory protein interacting with SOX2 (Engelen et al., 2011). In mouse models carrying Chd7 mutations, Otx2 and Gbx2 expression boundaries are shifted posteriorly, similarly to what we find in Sox2 mutants (Supporting Information Fig.S1), and CHD7 directly binds to the Otx2 and Gbx2 regulatory regions (Yu et al., 2013), on sites at least partially overlapping those bound by SOX2 (Engelen et al., 2011; Lodato et al., 2013; Yu et al., 2013). This suggests that a shared SOX2 and CHD7-controlled gene regulatory network, involving early Otx2 and Gbx2 regulation, may contribute to pathological features shared between the Sox2-deficiency and the CHARGE human syndromes. Vermis hypoplasia is also characteristic of Joubert and Meckel syndromes (JMS), caused by mutation of several different genes (Aguilar et al., 2012); interestingly, SOX2 ChIPseq experiments on cultured neural stem cells (NSC) (Engelen et al., 2011; Lodato et al., 2013) detect SOX2 binding to the promoter or to other gene sequences of various JMS genes (8 out of 17 JMS genes, mentioned in Aguilar et al., 2012, carry SOX2-bound promoters), a finding that was confirmed in studies of mouse brain-derived NSC (our unpublished observations), suggesting that Sox2 may be involved in a wider gene regulatory network regulating vermis development. Future experiments will address whether deregulation of these genes could also contribute to the cerebellar abnormalities in our mutants.

Taken together, these previous results suggest that the ataxic features observed in our Wnt1Cre Sox2-mutant mice are due, at least in part, to the abnormalities that we observe in the vermis at birth. However, it is important to note that functional motor abnormalities are observed, although in a milder form, also in mice in which Sox2 ablation was specifically obtained after birth, and were not therefore related to any vermis morphological abnormality. This point is further discussed below. 


\section{The relation between ataxia and Bergmann glia abnormalities}

The observed BG abnormalities raise the issue of their possible direct involvement in the ataxia found in Sox2 mutants. Sox2 is expressed in BG postnatally (Fig. 3). BG ectopic location and cellular dysmorphology is observed in both embryonic (Wnt1-Cre) and postnatal (GLASTCreERT2) Sox2 mutants, (Figs. 4,6), beginning after the first week of postnatal life; it is first detected at P19, and persists in adults (8 months and later). Similarly to embryonic Sox2 deletion, postnatal Sox2 deletion specifically in BG leads to ataxic features (Fig. 7), although the severity of the motor control defect is reduced compared to that observed in embryonic Sox2 mutants (Fig. 1e,f); note, however, that in postnatal mutants, the deletion of Sox2 in BG is incomplete (60-80\%, Fig. 6), which may explain, in part, the milder phenotype. It is important to note that, in postnatal cerebellum, only BG and other glial cells, but neither PC nor other neurons, express Sox2; in addition, only BG, but not other types of glial cells, show obvious abnormalities. This points to BG as a likely contributor to the functional abnormalities observed in Sox2 mutants, both prenatal (Wnt1-Cre) and, in particular, postnatal (GLASTCreERT2).

Mutation of other mouse genes leads to BG cytoarchitectural defects comparable to those in our mutants, accompanied by ataxia. Inactivation in BG (via a GFAP-Cre transgene) of the tumor suppressor adenomatous polyposis coli (APC) gene, encoding an inhibitor of the Wnt/beta-catenin pathway, disrupts BG architecture after P10, with translocation of their cell bodies to the molecular layer, loss of their pial contact and transformation into stellateshaped cells, leading to motor coordination deficits (X. Wang, Imura, Sofroniew, \& Fushiki, 2011). The Sox4 transcription factor gene is expressed in normal BG; intriguingly, its overexpression, in BG, via a hGFAP promoter leads to BG cytoarchitectural defects, resulting in ataxia (Hoser et al., 2007). Interestingly, ChIP studies (Lodato et al., 2013, and our 
unpublished observations) show binding of Sox 2 to the promoter regions of Sox 4 and APC, suggesting a possible direct regulation. It is interesting to note that, in our GLASTCreERT2 Sox2 mutant, the Sox2 deletion occurred in a subpopulation of the glial cells, BG and astroglia; the displaced BG cells included both Sox2-null and Sox2-positive cells. This result implies that non-cell autonomous mechanisms might be involved in causing cells which retain Sox2 expression to migrate away from their normal location along the PCL. As shown in Supplementary Table 3, glial cells express many Sox2-bound genes encoding diffusible factors, whose deregulated expression, following Sox2 ablation in glia, might thus affect the localization of both Sox2-deleted and non-deleted BG cells.

BG is known to play critical roles for the functionality of PCs in the mature cerebellum, and its defects have been shown to lead to ataxia by non-cell-autonomous mechanisms, whereby BG defects caused PC dysfunction. Indeed, mutant ataxin 7 (causing the autosomal dominant disease spinocerebellar ataxia 7, SCA7) caused neuronal degeneration when expressed in mouse BG via a cell-type-specific transgene (Custer et al., 2006), and mutant ataxin-1 (causing SCA1), when expressed in BG, contributed to non-cell-autonomous toxicity affecting PCs (Shiwaku et al., 2010). In our experiments, a proportion of the PC show aberrant postsynaptic currents of the PF-PC synapse, as expected given the connection between regulatory circuits operating in BG, and PC physiology (Fig. 5); on the other hand, the majority of responses were normal, perhaps reflecting the patchy distribution of ectopic BG.

How BG alterations relate to the PC disturbed function in Sox2-mutant cerebellum, is difficult to speculate at the present time. One important fact might be the loss of the normally close apposition of many BG cells relative to PC in the mutant cerebellum. Additionally, the presence of aberrant postsynaptic responses at the PF-PC synapse, suggests that the dysregulation of BG-PC signalling might have impaired the normal homeostasis based on a 
balance between synaptic potentiation and depression, leading to the generation of improper cortical output signals by the affected PCs.

Collectively, our results demonstrate a novel role of Sox2 in the maintenance of morphology and localization of $\mathrm{BG}$, as well as on at least one major biochemical activity (gliosome glutamate uptake) of these cells. Further, gene expression analysis of Sox2 mutant glia identifies a large number of potential direct Sox2 target genes (Supplementary Table 3), and point to a gene regulatory network that connects Sox2 to the regulation of other genes important in BG maintenance and in ataxia. Identifying the downstream targets of Sox 2 which are responsible, in Sox2 mutants, for the observed BG abnormalities, will be important for a better understanding of mechanisms operating in BG cells to affect PC function.

Future studies will clarify whether Sox2 expression is somehow altered in BG in ataxias occurring in man; additionally, it is possible that some of the transcriptional targets of Sox2 are among the genes whose activity is altered in ataxias. The future characterization and understanding of the Sox2-dependent regulatory network in BG might hopefully provide novel targets and new perspectives for therapeutic approaches.

\section{References}

Acampora, D., Avantaggiato, V., Tuorto, F., \& Simeone, A. (1997). Genetic control of brain morphogenesis through Otx gene dosage requirement. Development, 124(18), 36393650.

Aguilar, A., Meunier, A., Strehl, L., Martinovic, J., Bonniere, M., Attie-Bitach, T., . . Spassky, N. (2012). Analysis of human samples reveals impaired SHH-dependent cerebellar development in Joubert syndrome/Meckel syndrome. Proceedings of the National Academy of Sciences of the United States of America, 109(42), 16951-16956. doi: 10.1073/pnas.1201408109 
Avilion, A. A., Nicolis, S. K., Pevny, L. H., Perez, L., Vivian, N., \& Lovell-Badge, R. (2003). Multipotent cell lineages in early mouse development depend on SOX2 function. Genes \& development, 17(1), 126-140. doi: 10.1101/gad.224503

Bachleda, A. R., Pevny, L. H., \& Weiss, E. R. (2016). Sox2-Deficient Muller Glia Disrupt the Structural and Functional Maturation of the Mammalian Retina. Invest Ophthalmol Vis Sci, 57(3), 1488-1499. doi: 10.1167/iovs.15-17994

Basson, M. A., \& Wingate, R. J. (2013). Congenital hypoplasia of the cerebellum: developmental causes and behavioral consequences. Front Neuroanat, 7, 29. doi: 10.3389/fnana.2013.00029

Bertolini, J., Mercurio, S., Favaro, R., Mariani, J., Ottolenghi, S., Nicolis, S.K. (2016). Sox2dependent regulation of neural stem cells and CNS development. In H. Kondoh, LovellBadge, R. (Ed.), Sox2, Biology and role in development and disease: Elsevier.

Bradford, M. M. (1976). A rapid and sensitive method for the quantitation of microgram quantities of protein utilizing the principle of protein-dye binding. Anal Biochem, 72, 248-254.

Broccoli, V., Boncinelli, E., \& Wurst, W. (1999). The caudal limit of Otx2 expression positions the isthmic organizer. Nature, 401(6749), 164-168. doi: 10.1038/43670

Buffo, A., Rite, I., Tripathi, P., Lepier, A., Colak, D., Horn, A. P., . . Gotz, M. (2008). Origin and progeny of reactive gliosis: A source of multipotent cells in the injured brain. Proceedings of the National Academy of Sciences of the United States of America, 105(9), 3581-3586. doi: 10.1073/pnas.0709002105

Buffo, A., \& Rossi, F. (2013). Origin, lineage and function of cerebellar glia. Prog Neurobiol, 109, 42-63. doi: 10.1016/j.pneurobio.2013.08.001

Carney, K. E., Milanese, M., van Nierop, P., Li, K. W., Oliet, S. H., Smit, A. B., . . Verheijen, M. H. (2014). Proteomic analysis of gliosomes from mouse brain: identification and investigation of glial membrane proteins. J Proteome Res, 13(12), 5918-5927. doi: $10.1021 /$ pr500829z

Cavallaro, M., Mariani, J., Lancini, C., Latorre, E., Caccia, R., Gullo, F., . . Nicolis, S. K. (2008). Impaired generation of mature neurons by neural stem cells from hypomorphic Sox2 mutants. Development, 135(3), 541-557. doi: 10.1242/dev.010801

Cupolillo, D., Hoxha, E., Faralli, A., De Luca, A., Rossi, F., Tempia, F., \& Carulli, D. (2016). Autistic-Like Traits and Cerebellar Dysfunction in Purkinje Cell PTEN Knock-Out Mice. Neuropsychopharmacology, 41(6), 1457-1466. doi: 10.1038/npp.2015.339

Custer, S. K., Garden, G. A., Gill, N., Rueb, U., Libby, R. T., Schultz, C., . . La Spada, A. R. (2006). Bergmann glia expression of polyglutamine-expanded ataxin-7 produces neurodegeneration by impairing glutamate transport. Nature neuroscience, 9(10), 1302-1311. doi: 10.1038/nn1750

Danielian, P. S., Muccino, D., Rowitch, D. H., Michael, S. K., \& McMahon, A. P. (1998). Modification of gene activity in mouse embryos in utero by a tamoxifen-inducible form of Cre recombinase. Current biology : CB, 8(24), 1323-1326.

Dennert, N., Engels, H., Cremer, K., Becker, J., Wohlleber, E., Albrecht, B., . . Zink, A. M. (2017). De novo microdeletions and point mutations affecting SOX2 in three individuals with intellectual disability but without major eye malformations. Am J Med Genet A, 173(2), 435-443. doi: 10.1002/ajmg.a.38034

Engelen, E., Akinci, U., Bryne, J. C., Hou, J., Gontan, C., Moen, M., . . Poot, R. A. (2011). Sox2 cooperates with Chd7 to regulate genes that are mutated in human syndromes. Nature genetics, 43(6), 607-611. doi: 10.1038/ng.825 
Favaro, R., Valotta, M., Ferri, A. L., Latorre, E., Mariani, J., Giachino, C., . . Nicolis, S. K. (2009). Hippocampal development and neural stem cell maintenance require Sox2-dependent regulation of Shh. Nature neuroscience, 12(10), 1248-1256. doi: 10.1038/nn.2397

Ferri, A., Favaro, R., Beccari, L., Bertolini, J., Mercurio, S., Nieto-Lopez, F., . . . Nicolis, S. K. (2013). Sox2 is required for embryonic development of the ventral telencephalon through the activation of the ventral determinants Nkx2.1 and Shh. Development, 140(6), 1250-1261. doi: 10.1242/dev.073411

Ferri, A. L., Cavallaro, M., Braida, D., Di Cristofano, A., Canta, A., Vezzani, A., . . Nicolis, S. K. (2004). Sox2 deficiency causes neurodegeneration and impaired neurogenesis in the adult mouse brain. Development, 131(15), 3805-3819. doi: 10.1242/dev.01204

Fuca, E., Guglielmotto, M., Boda, E., Rossi, F., Leto, K., \& Buffo, A. (2017). Preventive motor training but not progenitor grafting ameliorates cerebellar ataxia and deregulated autophagy in tambaleante mice. Neurobiol Dis, 102, 49-59. doi: 10.1016/j.nbd.2017.02.005

Gritti, A., Parati, E. A., Cova, L., Frolichsthal, P., Galli, R., Wanke, E., . . Vescovi, A. L. (1996). Multipotential stem cells from the adult mouse brain proliferate and self-renew in response to basic fibroblast growth factor. The Journal of neuroscience : the official journal of the Society for Neuroscience, 16(3), 1091-1100.

Hilber, P., \& Caston, J. (2001). Motor skills and motor learning in Lurcher mutant mice during aging. Neuroscience, 102(3), 615-623.

Hoffmann, S. A., Hos, D., Kuspert, M., Lang, R. A., Lovell-Badge, R., Wegner, M., \& Reiprich, S. (2014). Stem cell factor Sox2 and its close relative Sox3 have differentiation functions in oligodendrocytes. Development, 141(1), 39-50. doi: 10.1242/dev.098418

Hoser, M., Baader, S. L., Bosl, M. R., Ihmer, A., Wegner, M., \& Sock, E. (2007). Prolonged glial expression of Sox 4 in the CNS leads to architectural cerebellar defects and ataxia. The Journal of neuroscience : the official journal of the Society for Neuroscience, 27(20), 5495-5505. doi: 10.1523/JNEUROSCI.1384-07.2007

Jayadev, S., \& Bird, T. D. (2013). Hereditary ataxias: overview. Genet Med, 15(9), 673-683. doi: 10.1038/gim.2013.28

Joyner, A. L., Liu, A., \& Millet, S. (2000). Otx2, Gbx2 and Fgf8 interact to position and maintain a mid-hindbrain organizer. Curr Opin Cell Biol, 12(6), 736-741.

Koirala, S., \& Corfas, G. (2010). Identification of novel glial genes by single-cell transcriptional profiling of Bergmann glial cells from mouse cerebellum. PLoS One, 5(2), e9198. doi: 10.1371/journal.pone.0009198

Leto, K., Arancillo, M., Becker, E. B., Buffo, A., Chiang, C., Ding, B., . . . Hawkes, R. (2016). Consensus Paper: Cerebellar Development. Cerebellum, 15(6), 789-828. doi: 10.1007/s12311-015-0724-2

Lewis, A. E., Vasudevan, H. N., O'Neill, A. K., Soriano, P., \& Bush, J. O. (2013). The widely used Wnt1-Cre transgene causes developmental phenotypes by ectopic activation of Wnt signaling. Developmental biology, 379(2), 229-234. doi: 10.1016/j.ydbio.2013.04.026

Li, B., \& Dewey, C. N. (2011). RSEM: accurate transcript quantification from RNA-Seq data with or without a reference genome. BMC Bioinformatics, 12, 323. doi: 10.1186/1471-210512-323

Li, J. Y., Lao, Z., \& Joyner, A. L. (2002). Changing requirements for Gbx2 in development of the cerebellum and maintenance of the mid/hindbrain organizer. Neuron, 36(1), 31-43.

Lodato, M. A., Ng, C. W., Wamstad, J. A., Cheng, A. W., Thai, K. K., Fraenkel, E., . . Boyer, L. A. (2013). SOX2 co-occupies distal enhancer elements with distinct POU factors in ESCs 
and NPCs to specify cell state. PLoS genetics, 9(2), e1003288. doi: 10.1371/journal.pgen.1003288

Martinez, S., Andreu, A., Mecklenburg, N., \& Echevarria, D. (2013). Cellular and molecular basis of cerebellar development. Front Neuroanat, 7, 18. doi: 10.3389/fnana.2013.00018

Milanese, M., Bonifacino, T., Fedele, E., Rebosio, C., Cattaneo, L., Benfenati, F., . . Bonanno, G. (2015). Exocytosis regulates trafficking of GABA and glycine heterotransporters in spinal cord glutamatergic synapses: a mechanism for the excessive heterotransporterinduced release of glutamate in experimental amyotrophic lateral sclerosis. Neurobiol Dis, 74, 314-324. doi: 10.1016/j.nbd.2014.12.004

Milanese, M., Zappettini, S., Jacchetti, E., Bonifacino, T., Cervetto, C., Usai, C., \& Bonanno, G. (2010). In vitro activation of GAT1 transporters expressed in spinal cord gliosomes stimulates glutamate release that is abnormally elevated in the SOD1/G93A(+) mouse model of amyotrophic lateral sclerosis. J Neurochem, 113(2), 489-501. doi: 10.1111/j.1471-4159.2010.06628.x

Milanese, M., Zappettini, S., Onofri, F., Musazzi, L., Tardito, D., Bonifacino, T., . . Bonanno, G. (2011). Abnormal exocytotic release of glutamate in a mouse model of amyotrophic lateral sclerosis. J Neurochem, 116(6), 1028-1042. doi: 10.1111/j.14714159.2010.07155.x

Miyazaki, T., Yamasaki, M., Hashimoto, K., Kohda, K., Yuzaki, M., Shimamoto, K., .. Watanabe, M. (2017). Glutamate transporter GLAST controls synaptic wrapping by Bergmann glia and ensures proper wiring of Purkinje cells. Proceedings of the National Academy of Sciences of the United States of America, 114(28), 7438-7443. doi: 10.1073/pnas.1617330114

Mori, T., Tanaka, K., Buffo, A., Wurst, W., Kuhn, R., \& Gotz, M. (2006). Inducible gene deletion in astroglia and radial glia--a valuable tool for functional and lineage analysis. Glia, 54(1), 21-34. doi: 10.1002 /glia.20350

Pevny, L. H., \& Nicolis, S. K. (2010). Sox2 roles in neural stem cells. The international journal of biochemistry \& cell biology, 42(3), 421-424. doi: 10.1016/j.biocel.2009.08.018

Ragge, N. K., Lorenz, B., Schneider, A., Bushby, K., de Sanctis, L., de Sanctis, U., . . Fitzpatrick, D. R. (2005). SOX2 anophthalmia syndrome. Am J Med Genet A, 135(1), 1-7; discussion 8. doi: 10.1002/ajmg.a.30642

Raiteri, L., Stigliani, S., Usai, C., Diaspro, A., Paluzzi, S., Milanese, M., . . Bonanno, G. (2008). Functional expression of release-regulating glycine transporters GLYT1 on GABAergic neurons and GLYT2 on astrocytes in mouse spinal cord. Neurochem Int, 52(1-2), 103112. doi: 10.1016/j.neuint.2007.04.027

Raiteri, L., Zappettini, S., Milanese, M., Fedele, E., Raiteri, M., \& Bonanno, G. (2007). Mechanisms of glutamate release elicited in rat cerebrocortical nerve endings by 'pathologically' elevated extraterminal K+ concentrations. J Neurochem, 103(3), 952961. doi: 10.1111/j.1471-4159.2007.04784.x

Shiwaku, H., Yoshimura, N., Tamura, T., Sone, M., Ogishima, S., Watase, K., . . Okazawa, H. (2010). Suppression of the novel ER protein Maxer by mutant ataxin-1 in Bergman glia contributes to non-cell-autonomous toxicity. The EMBO journal, 29(14), 2446-2460. doi: 10.1038/emboj.2010.116

Sisodiya, S. M., Ragge, N. K., Cavalleri, G. L., Hever, A., Lorenz, B., Schneider, A., . . Fitzpatrick, D. R. (2006). Role of SOX2 mutations in human hippocampal malformations and epilepsy. Epilepsia, 47(3), 534-542. doi: 10.1111/j.1528-1167.2006.00464.x 
Sottile, V., Li, M., \& Scotting, P. J. (2006). Stem cell marker expression in the Bergmann glia population of the adult mouse brain. Brain Res, 1099(1), 8-17. doi: 10.1016/j.brainres.2006.04.127

Stigliani, S., Zappettini, S., Raiteri, L., Passalacqua, M., Melloni, E., Venturi, C., . . Bonanno, G. (2006). Glia re-sealed particles freshly prepared from adult rat brain are competent for exocytotic release of glutamate. J Neurochem, 96(3), 656-668. doi: 10.1111/j.14714159.2005.03631.x

Sutter, R., Shakhova, O., Bhagat, H., Behesti, H., Sutter, C., Penkar, S., . . Marino, S. (2010). Cerebellar stem cells act as medulloblastoma-initiating cells in a mouse model and a neural stem cell signature characterizes a subset of human medulloblastomas. Oncogene, 29(12), 1845-1856. doi: 10.1038/onc.2009.472

Takayasu, Y., Iino, M., Kakegawa, W., Maeno, H., Watase, K., Wada, K., . . Ozawa, S. (2005). Differential roles of glial and neuronal glutamate transporters in Purkinje cell synapses. The Journal of neuroscience : the official journal of the Society for Neuroscience, 25(38), 8788-8793. doi: 10.1523/JNEUROSCI.1020-05.2005

Tarazona, S., Furio-Tari, P., Turra, D., Pietro, A. D., Nueda, M. J., Ferrer, A., \& Conesa, A. (2015). Data quality aware analysis of differential expression in RNA-seq with NOISeq R/Bioc package. Nucleic acids research, 43(21), e140. doi: 10.1093/nar/gkv711

Wang, V. Y., \& Zoghbi, H. Y. (2001). Genetic regulation of cerebellar development. Nat Rev Neurosci, 2(7), 484-491. doi: 10.1038/35081558

Wang, X., Imura, T., Sofroniew, M. V., \& Fushiki, S. (2011). Loss of adenomatous polyposis coli in Bergmann glia disrupts their unique architecture and leads to cell nonautonomous neurodegeneration of cerebellar Purkinje neurons. Glia, 59(6), 857-868. doi: 10.1002/glia.21154

Wassarman, K. M., Lewandoski, M., Campbell, K., Joyner, A. L., Rubenstein, J. L., Martinez, S., \& Martin, G. R. (1997). Specification of the anterior hindbrain and establishment of a normal mid/hindbrain organizer is dependent on Gbx2 gene function. Development, 124(15), 2923-2934.

Yu, T., Meiners, L. C., Danielsen, K., Wong, M. T., Bowler, T., Reinberg, D., . . Basson, M. A. (2013). Deregulated FGF and homeotic gene expression underlies cerebellar vermis hypoplasia in CHARGE syndrome. Elife, 2, e01305. doi: 10.7554/eLife.01305

Zappone, M. V., Galli, R., Catena, R., Meani, N., De Biasi, S., Mattei, E., . . Nicolis, S. K. (2000). Sox2 regulatory sequences direct expression of a (beta)-geo transgene to telencephalic neural stem cells and precursors of the mouse embryo, revealing regionalization of gene expression in CNS stem cells. Development, 127(11), 2367-2382.

Zhao, C., Ma, D., Zawadzka, M., Fancy, S. P., Elis-Williams, L., Bouvier, G., . . Franklin, R. J. (2015). Sox2 Sustains Recruitment of Oligodendrocyte Progenitor Cells following CNS Demyelination and Primes Them for Differentiation during Remyelination. The Journal of neuroscience : the official journal of the Society for Neuroscience, 35(33), 1148211499. doi: 10.1523/JNEUROSCI.3655-14.2015 


\section{Figure legends}

\section{Figure 1. Wnt1-Cre Sox2-mutant mice show defects in motor control and cerebellar} morphology

(a) Sox2 early conditional deletion in the midbrain-hindbrain. Sox2 in situ hybridization on E9.5 sagittal sections of control (Sox2F/F, left) and Sox2-deleted embryos (Sox2F/F;Cre, right) showing loss of Sox2 expression in the mid-hindbrain by E9.5. Fb: forebrain; Mes: mesencephalon; CbP: Cerebellar primordium.

(b-d) Motor performances of Sox2F/F;Cre mutants were evaluated at rotarod test (b) and beam test (c,d) and compared to control littermates (Sox2FF/F+, Sox2F/+;Cre) from 1 to 8 months of age. At the rotarod test, both Sox2F/F;Cre and Sox2F/+;Cre animals showed a significantly lower latency to fall compared to controls (b; Two-way Anova, main effect of genotype, $\mathrm{P}=0.0001$ ); at the beam test, Sox2F/F;Cre mutants overall made more slip errors (b;Two-way Anova, main effect of genotype, $\mathrm{P}=0.0001$ ) and took more time to cross the bar compared to controls (d, Two-way Anova, main effect of genotype, $\mathrm{P}=0.0001$; Time, Two-way Anova, main effect of genotype, $\mathrm{P}=0.0001$, main effect of time, $\mathrm{P}=0.002$ ). Details on statistical analysis are reported in Table 1.

$(e, f)$ Sox2 early conditional deletion leads to cerebellar morphological defects. (e) Cerebellar morphology at P5. Two Sox2F/F;Cre mutants are shown, with "moderate" (left) and "severe" (right) phenotype. Vertical arrows point to the antero-posterior extension of the vermis, reduced in the mutants. Some enlargement of the adjacent mesencephalic lobes is also seen in mutants, and in controls carrying the Cre transgene as previously described (Lewis, 
Vasudevan, O'Neill, Soriano, \& Bush, 2013). The lateral arrow in the second mutant ("severe") points to a central "hole" at the mid/hindbrain boundary. The severe phenotype was observed in 4/44 mutant mice examined (11\%). (f) Cerebellar morphology in adults, dorsal view; vermis lobules are numbered. In mutants, the vermis is reduced along the antero-posterior axis. Scale bars: A, $200 \mu \mathrm{M} ; \mathrm{B}, \mathrm{C}: 2 \mathrm{~mm}$.

Figure 2. Adult Wnt1Cre mutant mice show morphological alterations in the cerebellar vermis

(a-c) Sagittal sections of the cerebellar vermis of Sox2FF/F+ (a), Sox2F/+;Cre (b), and Sox2F/F;Cre (c) adult mice (8 months) display a reduction in size in the mutant accompanied by subtle alterations in defined fissures (asterisks in $\left.a^{\prime}, a^{\prime \prime}, b^{\prime}, b^{\prime \prime}, c^{\prime}, c^{\prime \prime}\right)$. (d) Morphometric measurements for each examined section comprised the evaluation of i) the PCL length along the entire section (green line); ii) the maximal extension along the Rostro-Caudal (R-C) axis axis, defined as the distance connecting the maximal convexity of the crowns of lobules $\mathrm{V}$ and $\mathrm{IXb}$, and the Ventro-Dorsal (V-D) axis, corresponding to the distance connecting the invagination between lobules I and X and the midpoint in the crown of lobule VIb (dotted lines, see Methods section); iii) the thickness of the GL in each lobule (red dotted line); iv) the PCL length along each lobule (green line between the two green crosses) and the extension of the fissures separating lobules IVa/VIb (yellow line) and lobules IXb/IXc (purple line). (e) The extension of the entire PCL is significantly diminished in Sox2F/F;Cre compared to both Sox2FF/F+ and Sox2F/+;Cre mice (One-way Anova, $\mathrm{P}=0.0026$ ). A reduction in size is also observed in the mutant R-C length (f; One-way Anova, $\mathrm{P}=0.0014$ ), whereas no differences are detected in the V-D extension (g), as well as in GL thickness (h). (i-k) PCL length declines in defined lobules of the mutant compared to controls (k, lobule IV-V, One-way Anova, P=0.0195; 
i, lobule VIb, One-way Anova, $\mathrm{P}=0.0084$; j, lobules IX and $\mathrm{X}$, One-way Anova, $\mathrm{P}=0.0055$ and $\mathrm{P}=0.0124$, respectively). (k-m) Mutant mice show fine alterations in foliation, as revealed by the absence of the fissure between lobules IXb/IXc (a", b", c" - violet asterisk -, l) and by the poor development of the fissure separating lobules VIa/VIb (a', b', c' - yellow asterisk -, M; One-way Anova, $\mathrm{P}=0.0411$ ). Dapi staining (blue in a-c") labels all cell nuclei and allows visualization of layering. Scale bars: a, b, c, $300 \mu \mathrm{m} ; \mathrm{a}^{\prime}, \mathrm{a}^{\prime \prime}, \mathrm{b}^{\prime}, \mathrm{b}^{\prime \prime}, \mathrm{c}^{\prime}, \mathrm{c}^{\prime \prime}, 100 \mu \mathrm{m}$. Details on statistical analysis are reported in Table $1 .{ }^{*} \mathrm{P}<0.05 ;{ }^{* *} \mathrm{P}<0.01 ; * * \mathrm{P}<0.001$.

\section{Figure 3. SOX2 expression in postnatal and adult cerebellum}

(a-f') Immunofluorescence for S0X2 (green) and glial (S100B, red), or neuronal (Calbindin, Calb, red) markers in the control (a-d"') and mutant (e-f') postnatal cerebellum. (a-b") SOX2 immunofluorescence (green) in the postnatal (P7) cerebellum shows SOX2 expression in S100B+ astrocytes(red in a-b'), i.e. BG cells in the PCL (arrowheads in b-b") and parenchymal astrocytes of the GL and PWM (arrows in b-b"). (c-c"') At P7, SOX2labelling is not detected in Calbindin+ PCs (red). (e-f') Absence of Sox2 expression in mutant Sox2F/F;Cre cerebella at both P7 (e,e') and 8 months (f,f'). ML, molecular layer; PCL, Purkinje cell layer, GL, granular layer, PWM, prospective white matter. Scale bars: A, D, E-F', $50 \mu \mathrm{m}$; B-C, D'-D'”, $20 \mu \mathrm{m}$; C'-C'”, $10 \mu \mathrm{m}$.

\section{Figure 4. Wnt1-Cre Sox2 mutants show postnatal BG alterations}

(a-r) Glial cells were labelled with specific markers as BLBP, S100B and GFAP in control (a-f, Sox2FF/F+; g-l, Sox2F/+;CRE) and in mutant (m-r, Sox2F/F;Cre) cerebella at different ages. At P7 (a-c; g-i; m-o) no significant differences were detected in BG progenitors distribution, as BG cells were similarly labelled with BLBP and S100B in the arising PCL of the three 
genotypes. At P19 (d-d"; j-j"; p-p") ectopic S100B+ cells appeared in the mutant ML (p-p"; arrows in p') and these cells ectopic remained in the adult cerebella at 8 months (arrows in q). GFAP staining confirmed the presence of mislocalized BG in the mutant ML, at both P19 and 8 months, and highlighted theaberrant multipolar morphology of these cells (arrowheads in p" and r; r'). (s) Quantification of S100B+ cells in 8 months old mutant or control cerebella confirmed the significant presence of ectopic BG cells in the mutant ML (Student T test, P < 0.0001; Sox2F/F;Cre mice vs. Sox2FF/F+ and Sox2F/+;Cre mice). (t,u) Analysis of cell density (n. of cells $/ \mathrm{mm}^{2}$ ) of S100B+ cells in the PCL and related ratio of S100B+ cells to PCs (u) showed a significant decrease of BG somata correctly aligned in the PCL ( $t$ ) of 8 months old mutant mice (Student $\mathrm{T}$ tests, $\mathrm{t}, \mathrm{P}=0.0179 ; \mathrm{u}, \mathrm{P}=0,0014$; Sox2F/F;Cre vs. Sox $2 \mathrm{FF} / \mathrm{F}+$ and Sox $2 \mathrm{~F} /+$; Cre mice). (s-u) Being fully comparable, data from the two control genotypes were pooled together (see Table 2). Dapi staining (blue in a,e,g,k,m,q) labels all cell nuclei. ML, molecular layer; PCL, Purkinje cell layer, GL, granular layer, WM, white matter. Scale bars: a, g, m, $100 \mu \mathrm{m}$; c, d-d", f, hj", l, o-p", r, $50 \mu \mathrm{m}$; b, $20 \mu \mathrm{m}$; e,k,q, $30 \mu \mathrm{m} ; \mathrm{n}, 10 \mu \mathrm{m}$. Details on statistical analysis are reported in Table $1 .{ }^{*} \mathrm{P}<0.05 ;{ }^{* *} \mathrm{P}<0.01 ;{ }^{* *} \mathrm{P}<0.001$.

\section{Figure 5. Alteration of the PF-EPSC in adult mutant mice}

(a) Five superimposed representative traces for control (blue; Sox2FF/F+) and mutant mice EPSCs (red; Sox2F/F;Cre) obtained with stimulus strengths from 3 to $15 \mu \mathrm{A}$. (b) Amplitudes of Parallel Fibre (PF)- Excitatory postsynaptic potentials (EPSCs) plotted as a function of stimulus intensity for control (Sox2FF/F+, blue circles, $\mathrm{n}=17$ ) and mutant (Sox2F/F;Cre; red triangles, $\mathrm{n}=16$ ) PCs. (c) Histogram distribution of EPSC amplitudes (obtained with stimulus strength of $12 \mu \mathrm{A}$ ) for control (c; Sox2FF/F+) and for mutant (d) mice. (e) Cumulative distribution of EPSC amplitudes for control (Sox2FF/F+, blue trace) and mutant mice 
(Sox2F/F;Cre, red trace) $(\mathrm{P}<0.0001$, Kolmogorov-Smirnov test). (f) Representative traces of PF-EPSCs evoked by paired-pulse stimulation with an interpulse interval of $100 \mathrm{~ms}$ in control (blue; Sox2FF/F+) and mutant mice (red; Sox2F/F;Cre). (g) Time course of paired-pulse facilitation of PF-EPSCs in control (Sox2FF/F+, blue circles, $\mathrm{n}=17$ ) and mutant mice (Sox2F/F;Cre, red triangles, $\mathrm{n}=16$ ). The facilitation is expressed as the percentage of the second EPSC relative to the first one (mean \pm SEM) and is plotted as a function of interstimulus interval.

\section{Figure 6. Postnatal Sox2 deletion in GLASTCreERT2Sox2 mutants causes BG alteration}

(a-d") Immunofluorescence analysis of Sox2F/F;CreERT2mutants after Tamoxifen (Tx) administration. P30 Sox2F/F;CreERT2 cerebella induced with Tx at P2 showed high numbers of mislocalized S100B+ BG in the ML (c-d"), most of which have lost Sox2 expression (arrows; arrowheads point to cells that maintained Sox2), compared to controls (a-b"). (d) A higher fraction of ectopic cells could be occasionally observed, within regions where Sox2 ablation had been particularly efficient (d-d"). (e) Quantification of Sox2-ablated cells. At P30, after tamoxifen administration at P2, a high percentage of S100B+ cells in Sox2F/F;CreERT2mutant cerebella does not express SOX2, in agreement with an efficient ablation of the gene. (f) Fraction of ectopic S100B+BGon total S100B+BGwas significantly higher in mutant Sox2F/F;CreERT2 cerebella induced at P2 with respect to control littermates at P30 (Student T test, $\mathrm{P}=0,0011$ ). (g-i) Ectopic $\mathrm{S} 100 \mathrm{~B}+\mathrm{BG}$ in the $\mathrm{ML}$ of mutant mice (arrows in $\mathrm{h}$ ) was maintained at 8 months after Tx treatment at P2 orat P8 plus P60 (P8-60). Controls include genotypes as for Table 2.Tx, tamoxifen; ML, molecular layer; PCL, Purkinje cell layer. Scale bars: a-d", $50 \mu \mathrm{m}$; g,h, $20 \mu \mathrm{m}$. Details on statistical analysis are reported in Table 1 . $^{*} \mathrm{P}<0.05$; $* * \mathrm{P}<0.01 ; * * * \mathrm{P}<0.001$. 
Figure 7. Postnatal Sox2 deletion in GLASTCreERT2 Sox2mutants causes motor control abnormalities

(a-d) Motor performances of Tx-treated Sox2F/F;CreERT2 mutants were evaluated with the beam $(a, b)$ and rotarod tests (c,d) and compared to those of control littermates (Controls, untreated) from 1 to 4 months of age. In the beam test, mutants of either sex exhibited slight alterations of motor behaviour compared to controls, as revealed by an increase in the number of slip errors (a, Two-way AnovaRM, Main effect of genotype, $\mathrm{P}<0.0454$ ) and in the time needed to cross the bar (b, Two-way AnovaRM, Main effect of time, $\mathrm{P}<0.0001)$. When all animals were pooled together, at the rotarod test no significant defects were detected in mutants, as showed by a similar latency to fall compared to controls (c). However, comparisons of mutant and control males highlighted that mutant males have a trend to perform in a worse way compared to controls (d, Two-way AnovaRM, Main effect of interaction of genotype per time, $\mathrm{P}<0.0001)$. (e,f) In the Open field test, both the distance travelled and the time spent in the center of the field were comparable in mutants and controls (Student $\mathrm{T}$ test, distance, $\mathrm{P}=0.802$; time, $\mathrm{P}=0.7957$ ). Further details on statistical analysis are reported in Supplementary Table 1.

Figure 8. Wnt1-Cre Sox2 mutants show gliosomal glutamate uptake alterations Gliosomes from control (Sox2FF/F+, blue circles) and mutant (Sox2F/F;Cre; orange circles) mice were exposed for $2 \mathrm{~min}$ at $37{ }^{\circ} \mathrm{C}$ to increasing concentration of $\left[{ }^{3} \mathrm{H}\right] \mathrm{D}$-Asp $(0.3,3,5,30$ and $100 \mu \mathrm{M}$ ). The specific glutamate uptake for each concentration tested is expressed as $\mathrm{nmol} / 2 \mathrm{~min}$. Values are expressed as $\mathrm{nmol} \mathrm{Glu} / \mathrm{mg}$ protein content / $2 \mathrm{~min}$ and are the mean \pm SEM of 5 independent experiments for each group. The kinetic parameters Vmax and Km 
values were obtained by fitting the points with the Michaelis-Menten equation $\left(\operatorname{Vmax}_{[\mathrm{Sox} 2 \mathrm{FF} / \mathrm{F}+]}=7.68 \pm 0.992 \mathrm{nmol} / \mathrm{mg} / 2 \mathrm{~min}, \quad \mathrm{n}=5 ; \quad \operatorname{Vmax}[\mathrm{Sox} 2 \mathrm{~F} / \mathrm{F} ;\right.$ Cre $] \quad=12.60 \pm 1.16$ $\mathrm{nmol} / \mathrm{mg} / 2 \min , \mathrm{n}=5) . \quad{ }^{*} \mathrm{P}<0.05\left(\mathrm{P}_{\mathrm{t}=-3.195=0.019)}\right.$ for $\operatorname{Vmax}[\mathrm{Sox} 2 \mathrm{FF} / \mathrm{F}+]$ Vs. Vmax[Sox2F/F;Cre] (two tailed Student's $t$-test). No significant differences were registered for $\mathrm{Km}$ values $\left(\mathrm{Km}_{[\mathrm{Sox} 2 \mathrm{FF} / \mathrm{F}+]}\right.$ $\left.=25.70 \pm 9.57 \mu \mathrm{M} \mathrm{n}=5 ; \mathrm{Km}_{[\mathrm{Sox} 2 \mathrm{~F} / \mathrm{F} ; \mathrm{Cre}]}=24.30 \pm 6.60 \mu \mathrm{M}, \mathrm{n}=5\right)$. 


\section{Supporting Information Figure and Table legends}

\section{Supporting Information Figure S1. In Sox2 mutants, Otx2 and Gbx2 show early alterations of expression boundaries}

(a,b) Otx2 and Gbx2 in situ hybridization on adjacent sagittal (a) or coronal (b) sections at E10.5 of mutants and controls (images of the mid-hindbrain boundary region are shown). (a) sagittal sections are shown at a lateral or medial level. Arrowheads point to the expression boundary of Otx2 or Gbx2, shifted posteriorly in mutants, evident in the medial region. A thinner neuroepithelium in mutants is visible in medial sections, corresponding to the prospective vermis region; this is reminiscent of a similar observation in the Gbx2 knock-out (J. Y. Li et al., 2002), reported to cause vermis hypoplasia. (b) Coronal sections. Arrowheads point to the posteriorly shifted boundary of Otx2 expression. Embryos shown in A and B are representative of: for coronal and sagittal sections analysis, respectively, $n=5$ and $n=4$ Sox2F/F;Cre mutants, $n=7$ and $n=3$ Sox2F/+;Cre heterozygotes, and $n=4$ and $n=4$ Sox2F/F or F/+ homozygous wild type controls. Ant: anterior; Post: posterior; Mes: mesencephalon; CbP: cerebellar primordium; Rho: rhomboencephalon (in green in b), which includes the cerebellar primordium; IVv: fourth ventricle. Scale bars: $200 \mu \mathrm{M}$.

\section{Supporting Information Figure S2. Wnt1-Cre Sox2 mutants do not show alterations in the density of Purkinje cells, interneurons or astrocytes in deep cerebellar layers}

(a,b) At 8 months of age, no significant differences were detected in the density of either CALBINDIN-positive Purkinje cells (a) or PARVALBUMIN-expressing molecular layer interneurons (b) between control (Sox2FF/F+ and Sox2F/+;Cre) and mutant animals 
(Sox2F/F;Cre). (c,d) Similar results were obtained for the density of S100B-positive astrocytes in the GL (c) and WM (d) at P19. DAPI staining (blue) labels all cell nuclei. GL, granular layer, WM, white matter, PCL, Purkinje cell layer, Calb, CALBINDIN, PV, PARVALBUMIN. Scale bars: $30 \mu \mathrm{m}$.

\section{Supporting Information Figure S3. Wnt1-Cre Sox2 mutants do not show alterations in} the density of cells in the oligodendroglial lineage or myelination defects

(a) At 10 weeks of age, staining for NG2 (a, red) did not reveal differences in the density of oligodendrocyte progenitors between mutant (Sox2F/F;Cre) and control (Sox2FF/F+ and Sox2F/+;Cre) mice, either in the molecular layer (ML, a'), or in the granular layer (GL, a") and white matter (WM, a'”). (b) Similarly, as revealed by GSTPi immunostaining (b, red), postmitotic differentiating oligodendrocytes showed comparable densities in all layers in both mutant and control mice (b',b"). These results were further confirmed by Olig2 immunostaining (c-c'”, red), which labels the entire oligodendrocyte lineage. (d-e) Anti-MBP immunofluorescence (red) was overall comparable in mutant (e) and control (d) mice, in both lobular (d',e') and deep (d", e') white matter. Dapi staining labels cell nuclei and allows layers visualization. ML, molecular layer, GL, granular layer, WM, white matter. Scale bars: a,b,c,d',d",e',e", $50 \mu \mathrm{m} ; \mathrm{d}, \mathrm{e}, 200 \mu \mathrm{m}$.

\section{Supporting Information Figure S4. Endogenous glutamate and glutamine} quantification. High performance liquid chromatography analysis of the cytosolic endogenous glutamate (a) and glutamine (b) content measured in gliosomes of BG cells purified from control (Sox2FF/F+, blue bars) and mutant (Sox2F/F;Cre; orange bars) mice. Endogenous glutamate (Glu) and glutamine (Gln) content are expressed as nmol/mg of 
gliosomal protein content and represent the mean \pm SEM of 5 independent experiments for each experimental group $\left(\mathrm{Glu}_{[\mathrm{Sox} 2 \mathrm{FF} / \mathrm{F}+]}=38.26 \pm 4.88 \mathrm{nmol} / \mathrm{mg}, \mathrm{n}=5 ; \quad \mathrm{Glu}_{[\mathrm{Sox} 2 \mathrm{~F} / \mathrm{F} ; \mathrm{Cre}]}=\right.$ 34.49 $\pm 5.01 \mathrm{nmol} / \mathrm{mg}, \quad \mathrm{n}=5 ; \quad \operatorname{Gln}[\operatorname{Sox} 2 \mathrm{FF} / \mathrm{F}+]=20.12 \pm 3.98 \mathrm{nmol} / \mathrm{mg}, \mathrm{n}=5 ; \quad \operatorname{Gln}[$ Sox $2 \mathrm{~F} / \mathrm{F} ; \mathrm{Cre}]=$ 24.94 $\pm 5.66 \mathrm{nmol} / \mathrm{mg}, \mathrm{n}=5$ ). (c) Endogenous cytosolic glutamate/glutamine content ratio in gliosomes of BG cells of control and mutant mice $\left(\mathrm{Glu} / \mathrm{Gln}_{[\mathrm{Sox} 2 \mathrm{FF} / \mathrm{F}+]}=2.07 \pm 0.23 \mathrm{nmol} / \mathrm{mg}, \mathrm{n}=5\right.$;

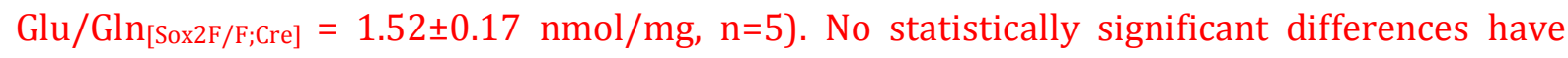
been detected.

\section{Supplementary Table 1 . Details of statistical analyses.}

In most cases only comparisons leading to $\mathrm{P}<0.05$ are reported; $\mathrm{n}=$ number of animals (unless differently stated). RM, repeated measures.

\section{Supplementary Table 2. Average numerical values obtained in immunofluorescence experiments, and statistical analysis.}

Supplementary Table 3. Genome-wide analysis of genes deregulated in glia following Sox2 loss, and their overlap with BG-expressed genes, and direct SOX2 binding

(a) "Expression" sheet: Output of the analysis performed by NOISeq (see Methods) on RNASeq data. Expression values, defined as Transcripts per Million (TPM) in three replicates of wild-type (WT 1-3) and Sox2-deleted cells (MUT 1-3). Genes are ordered according to significance of expression variation, from high to low. For each gene, the table reports: qvalue (1-FDR) output by NOISeq; the MUT/WT fold ratio; the significance of expression 
variation at a false discovery rate (FDR) threshold of 0.01 (SIGP, +1 over-expressed in MUT, -1 over-expressed in WT); whether or not the gene is included in the genes expressed in BG at postnatal day 6 (P6) (UP P6 column), at P30 (UP P30), or both (UP BOTH) (datasets from Koirala and Corfas 2010); whether or not the gene is SOX2-bound on the promoter or proximal enhancer (SOX2 in PROMOTER or SOX2 in ENHANCER) (dataset in Lodato et al., 2013). The significance of each overlap and corresponding p-values (columns $\mathrm{Y}$ to $\mathrm{AE}$ in "Expression" sheet) were computed with a hypergeometric test. Note that, in Koirala and Korfas (2011), UP P6 are genes expressed, in BG at P6, at levels at least 3 times higher that at P30; UP P30 are genes expressed at P30 at levels at least 3 times higher that at P6; UP BOTH are genes expressed at both stages.

(b) "Gene lists" sheet: Lists of genes deregulated (UP MUT or UP WT) in Sox2 deleted cells (columns A,B), and lists of genes belonging to the different classes defined by overlap of UP WT or UP MUT genes and genes expressed in BG (UP P6, UP P30, or UP BOTH), and/or SOX2bound genes (SOX2). Genes of known potential relevance for ataxia are in bold. 


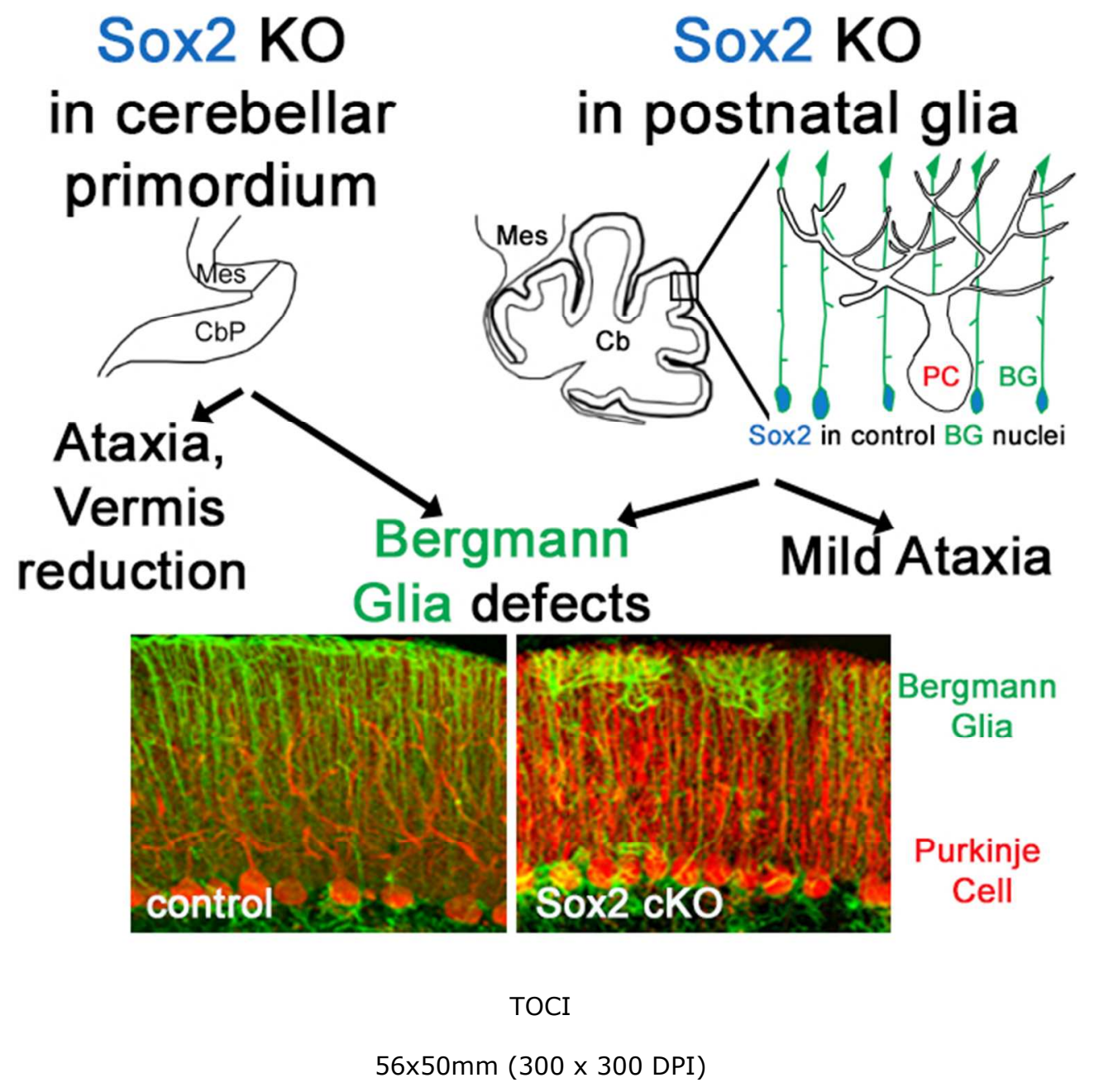



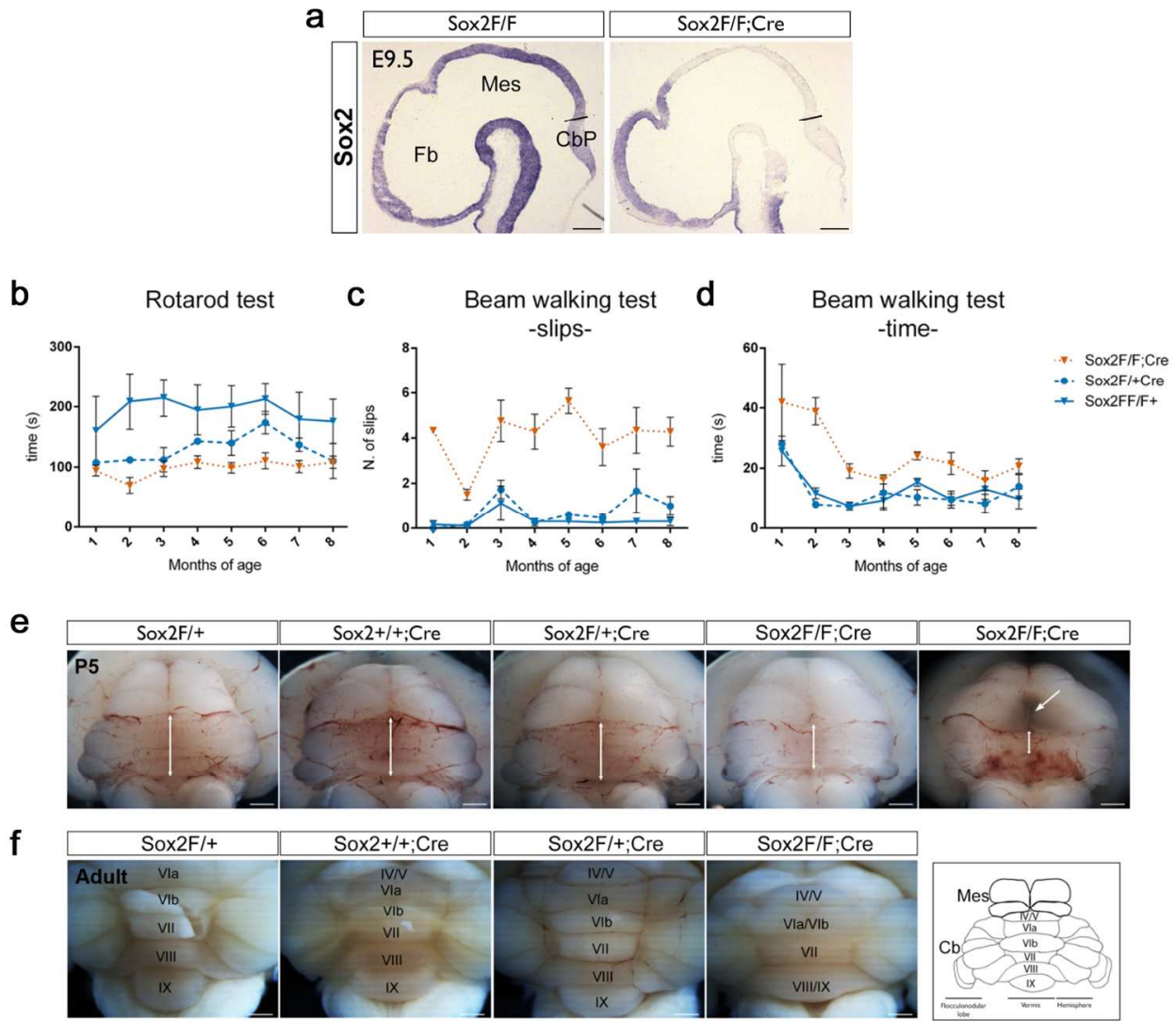

Figure 1

$160 \times 136 \mathrm{~mm}(300 \times 300$ DPI $)$ 

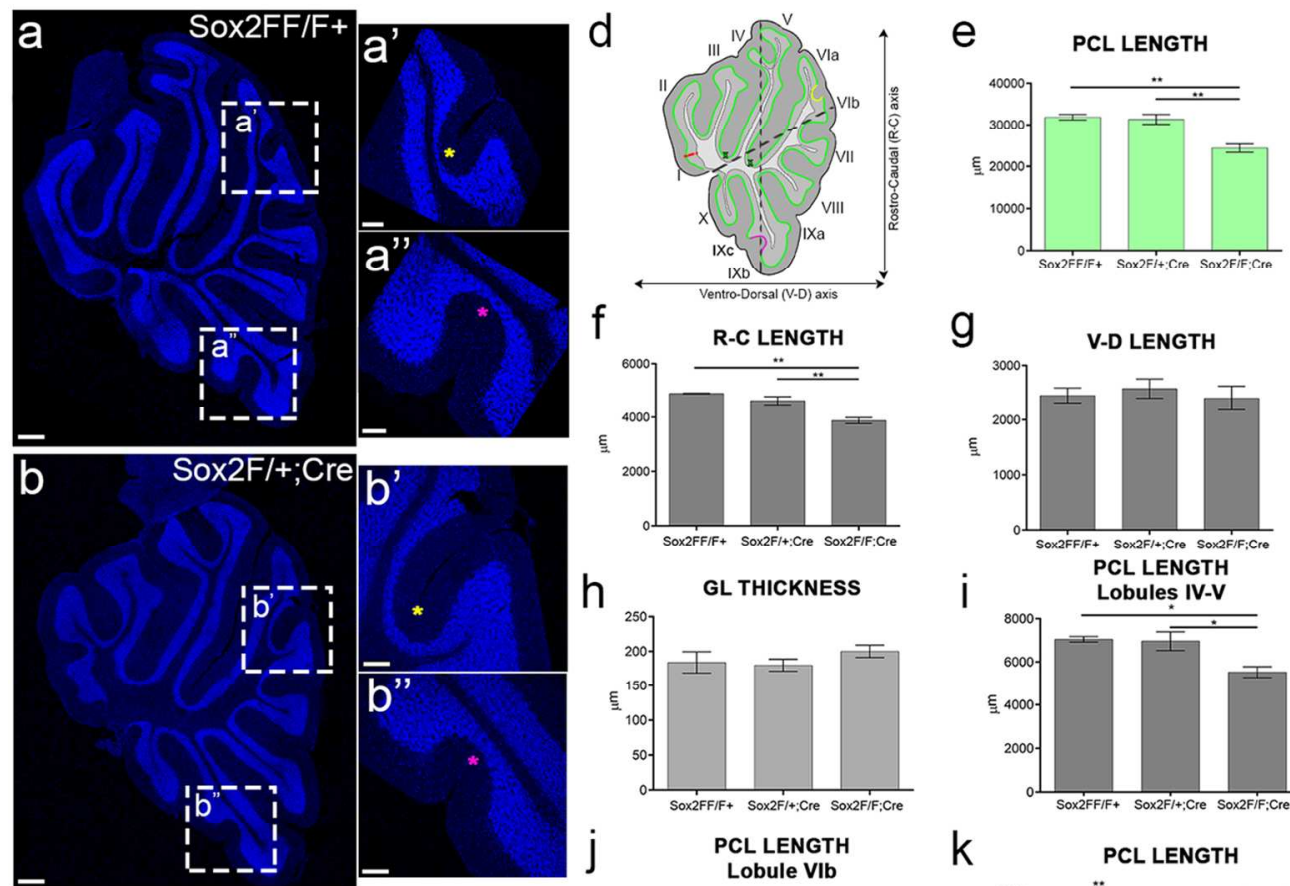

g
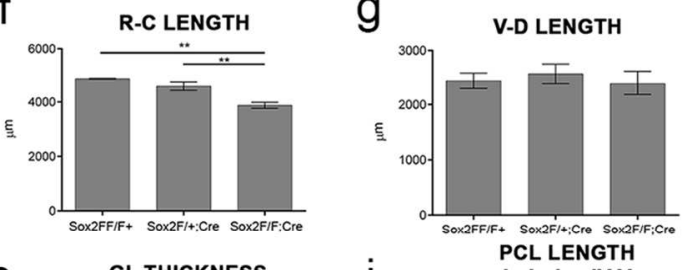

h

GL THICKNESS
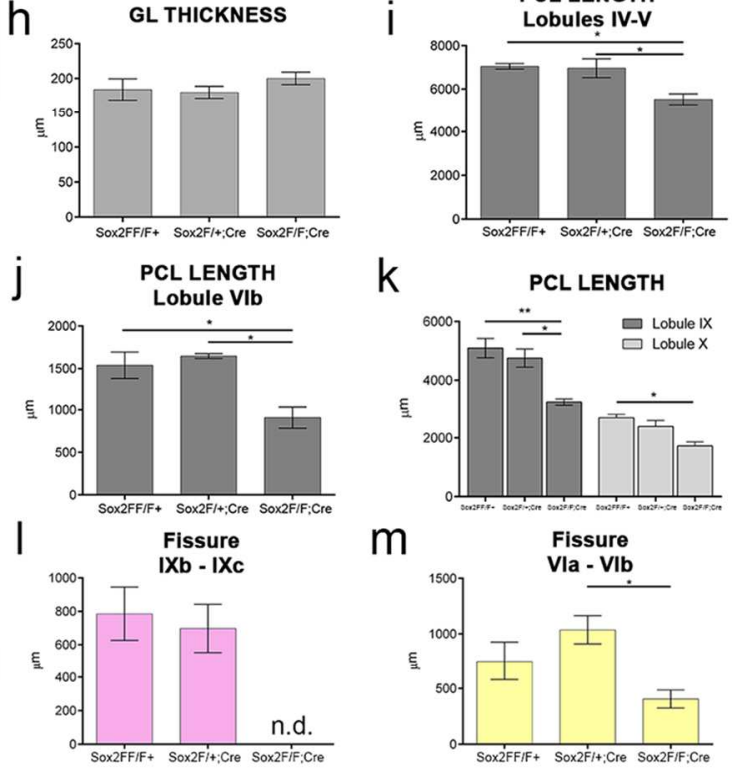

$\mathrm{k}$ PCL LENGTH
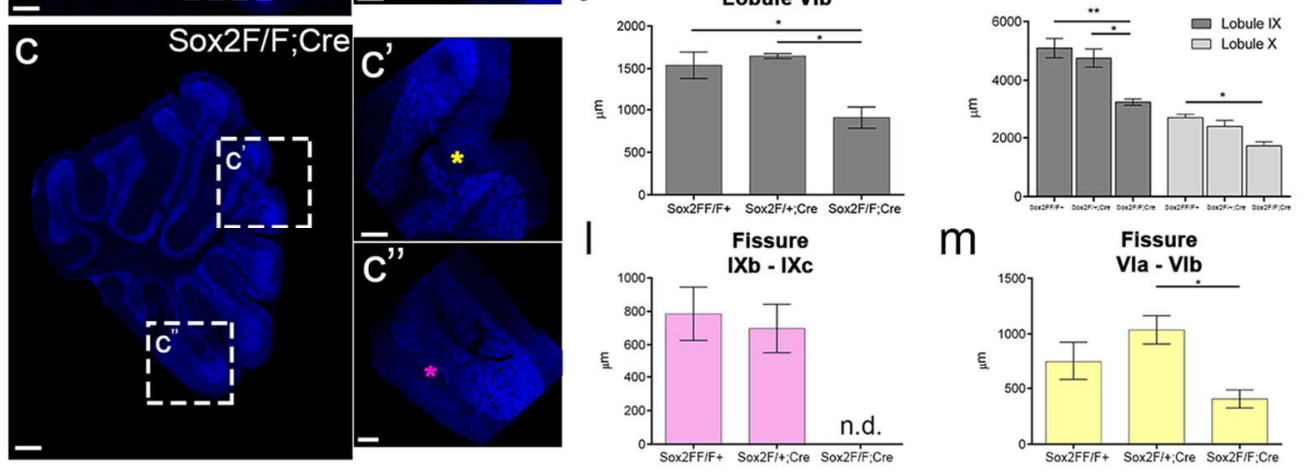

Figure 2

$109 \times 117 \mathrm{~mm}(300 \times 300 \mathrm{DPI})$ 


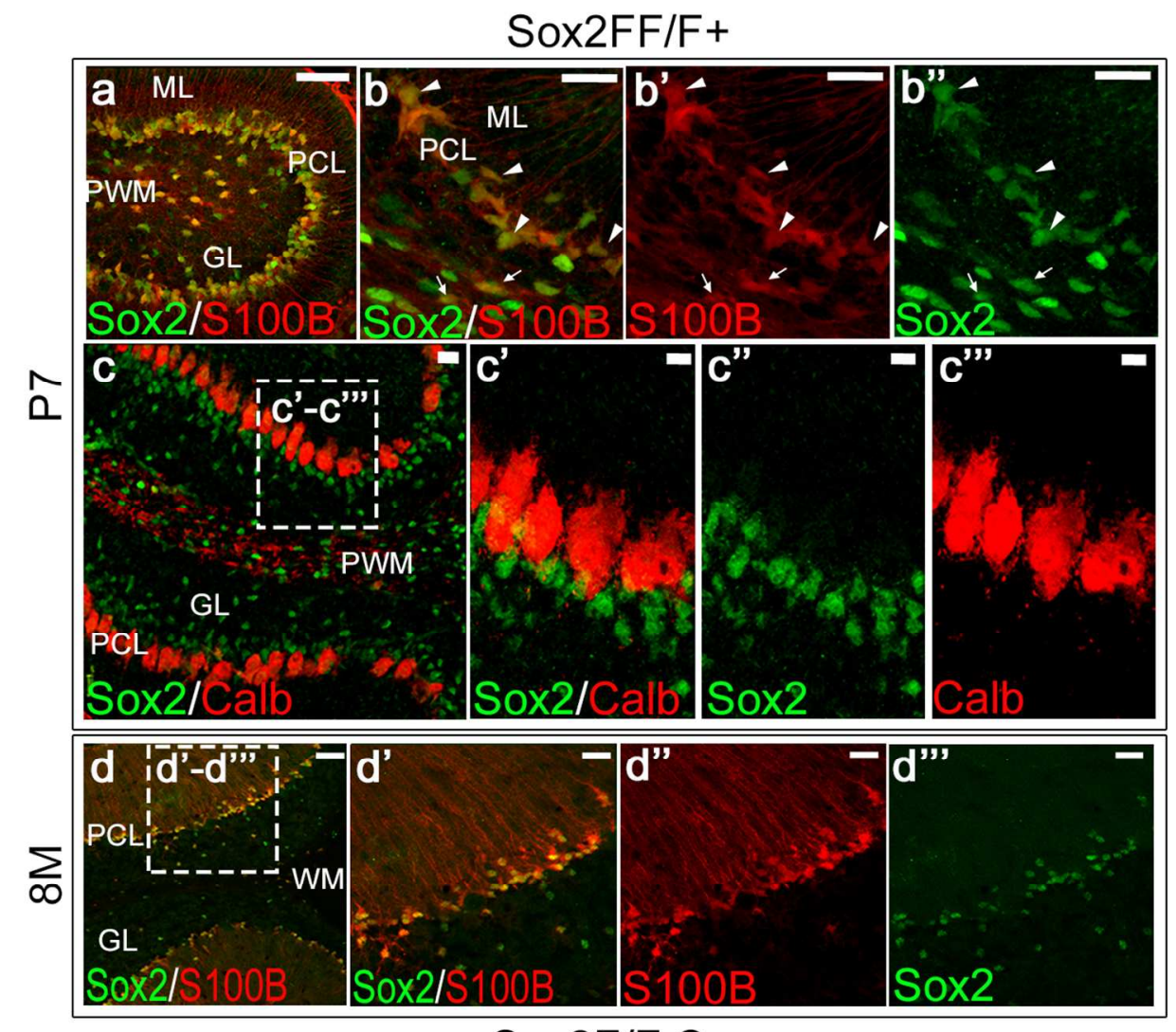

Sox2F/F;Cre

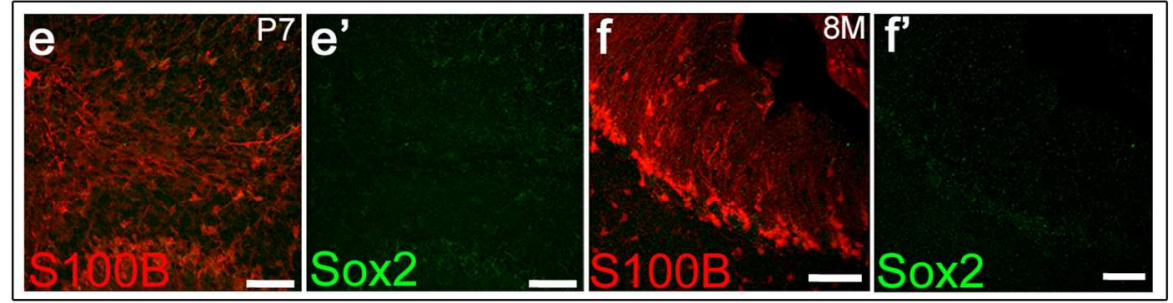

Figure 3

$115 \times 129 \mathrm{~mm}(300 \times 300 \mathrm{DPI})$ 


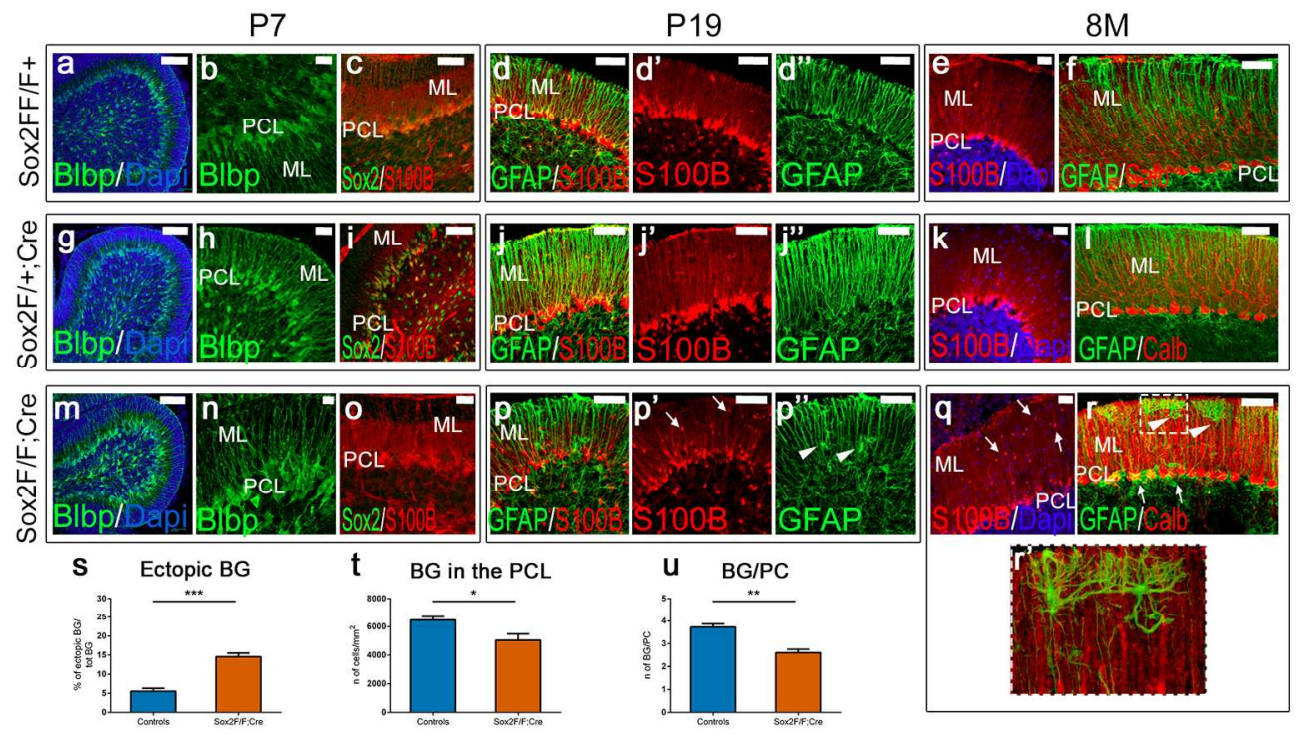

Figure 4

$172 \times 98 \mathrm{~mm}(300 \times 300 \mathrm{DPI})$ 
a
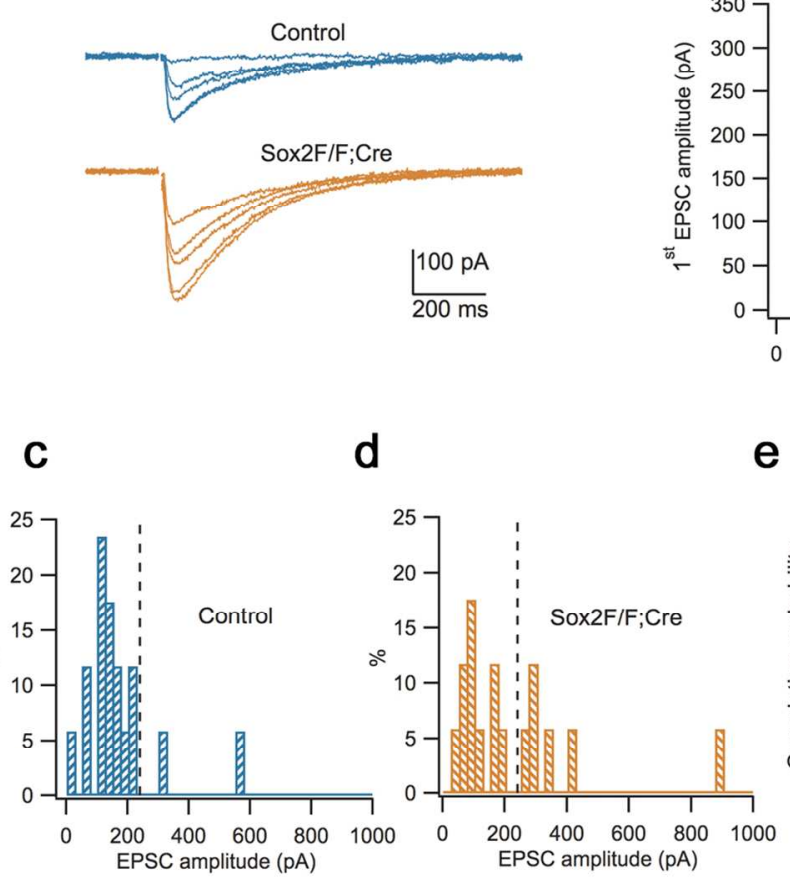

e b

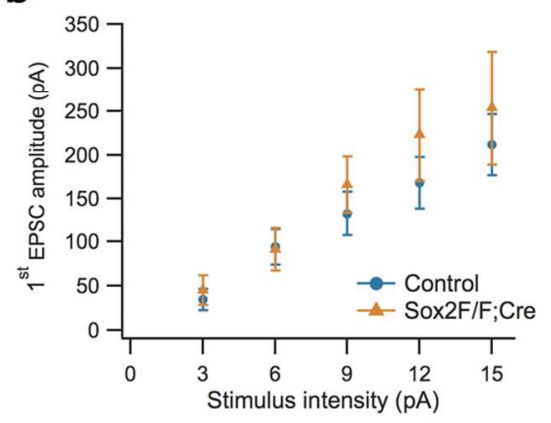

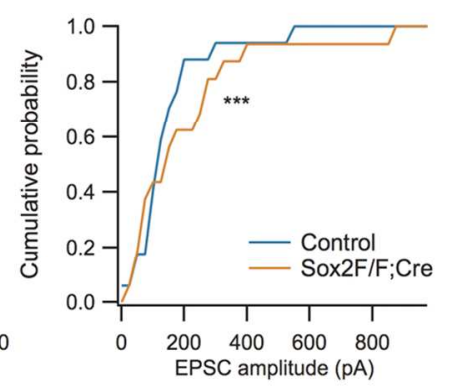

f

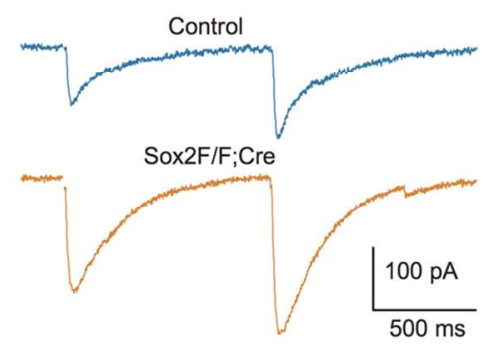

g

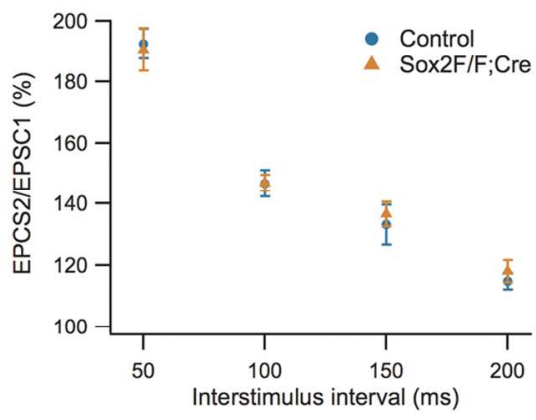

Figure 5

$115 \times 132 \mathrm{~mm}(300 \times 300$ DPI $)$ 


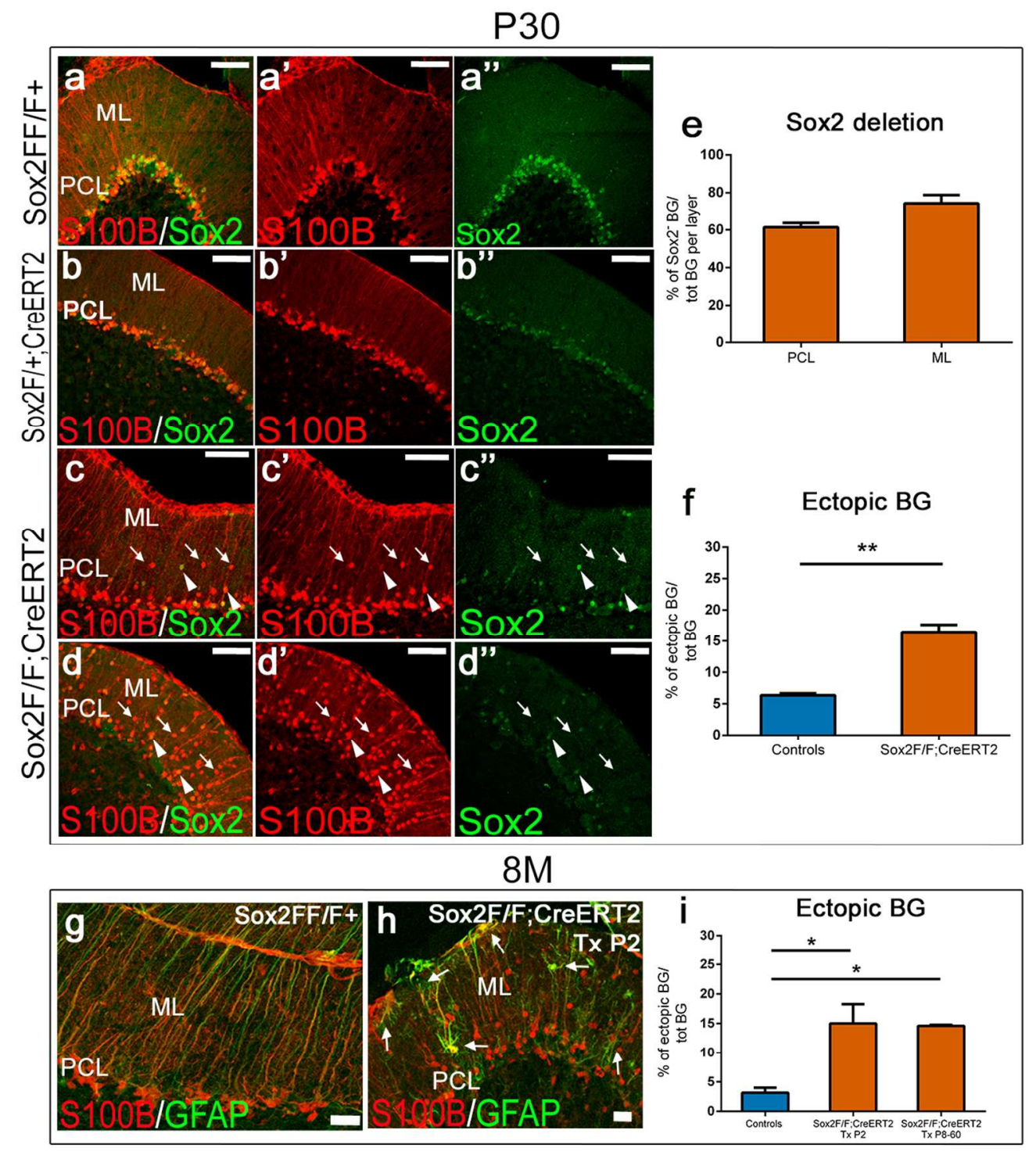

Figure 6

$115 \times 131 \mathrm{~mm}(300 \times 300$ DPI $)$ 
a

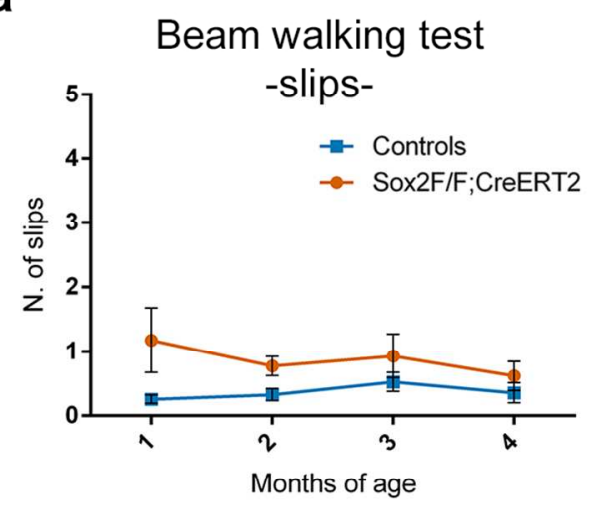

C

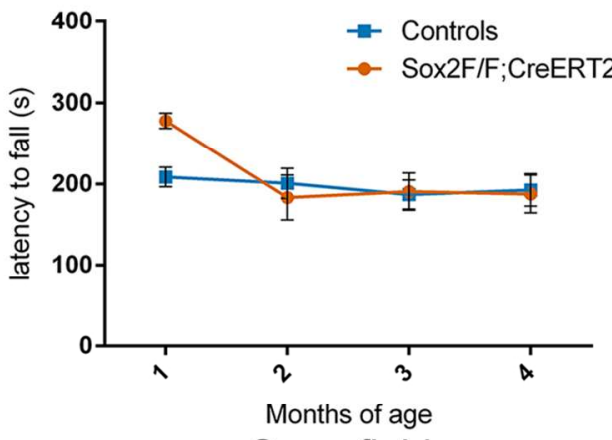

e

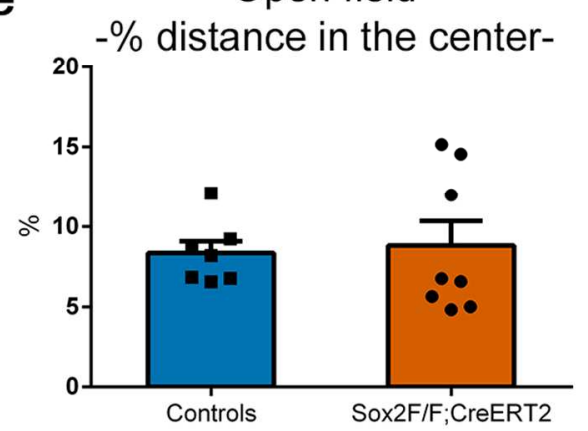

b
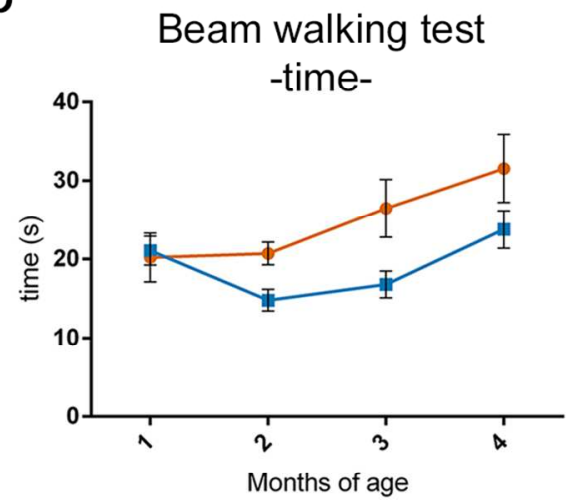

d

Rotarod test

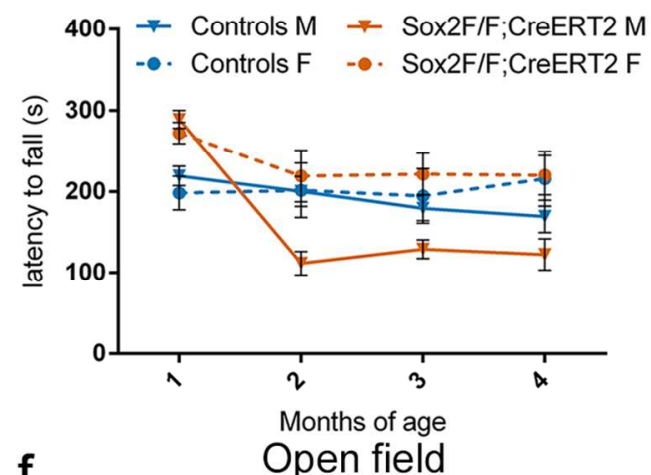

f

$-\%$ time in the center-

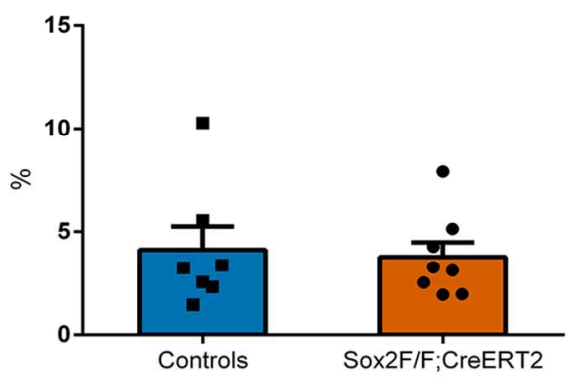

Figure 7

$113 \times 134 \mathrm{~mm}(300 \times 300$ DPI $)$ 


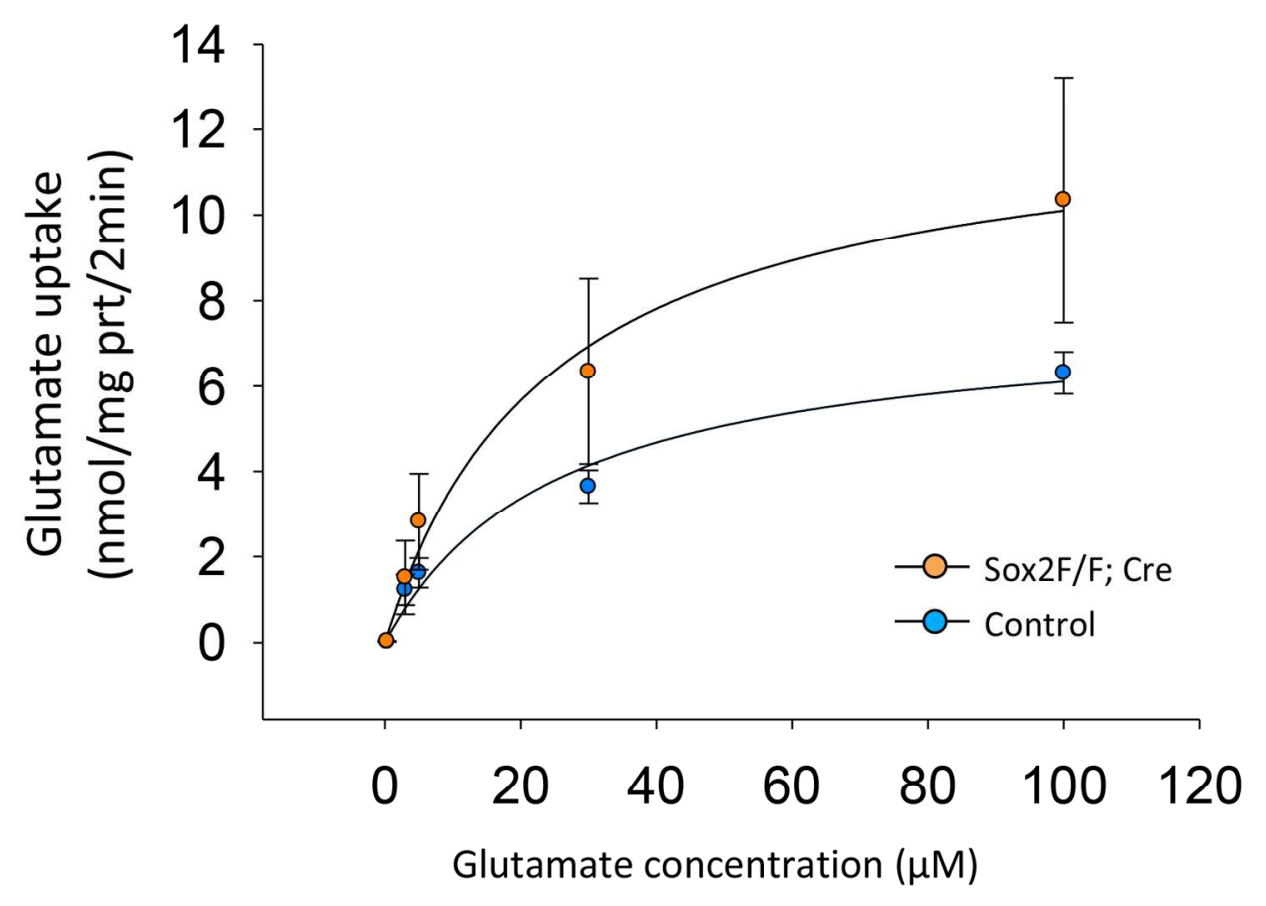

Figure 8

$149 \times 109 \mathrm{~mm}$ (300 x 300 DPI) 


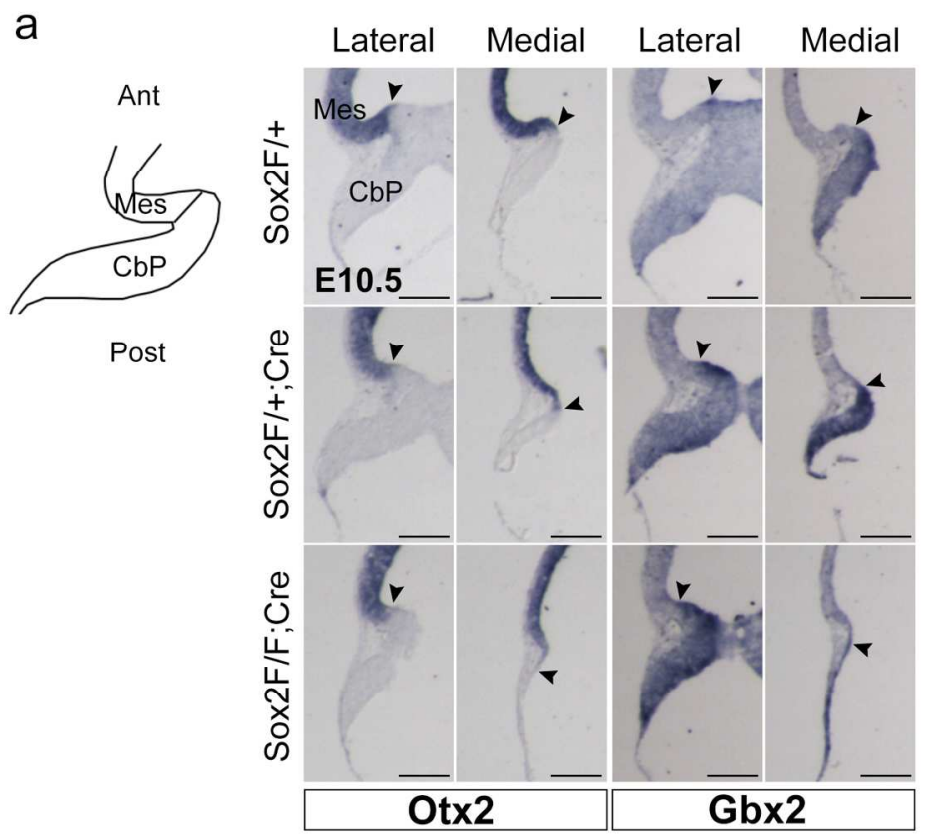

b

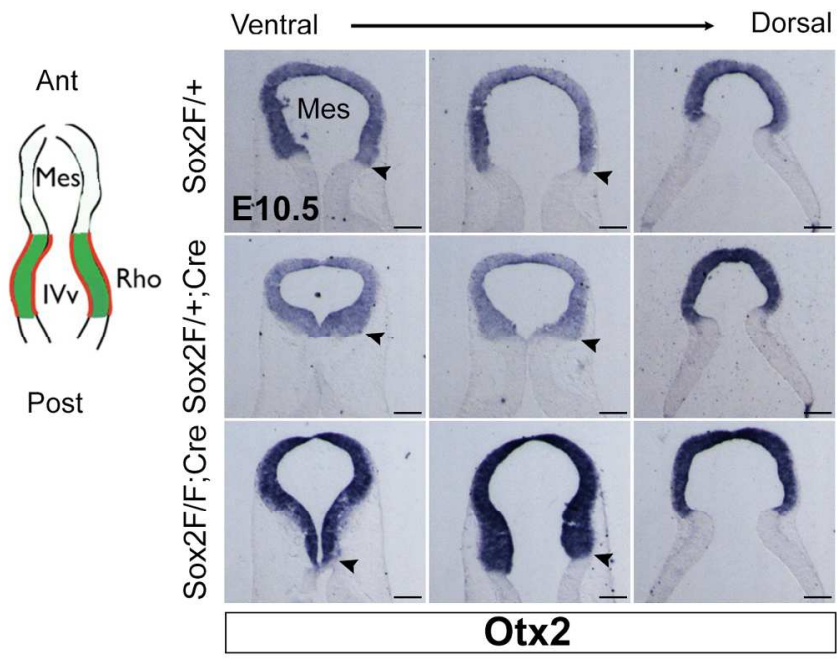

$118 \times 195 \mathrm{~mm}(300 \times 300$ DPI $)$ 

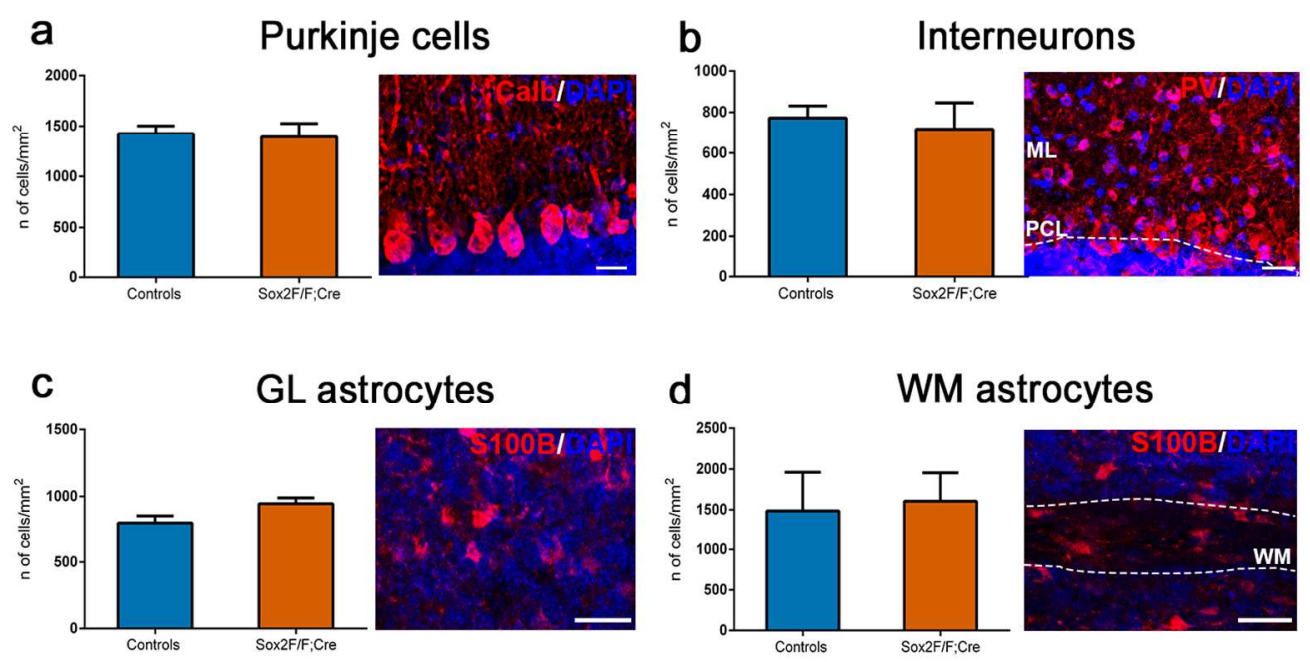

$128 \times 66 \mathrm{~mm}(300 \times 300$ DPI $)$ 


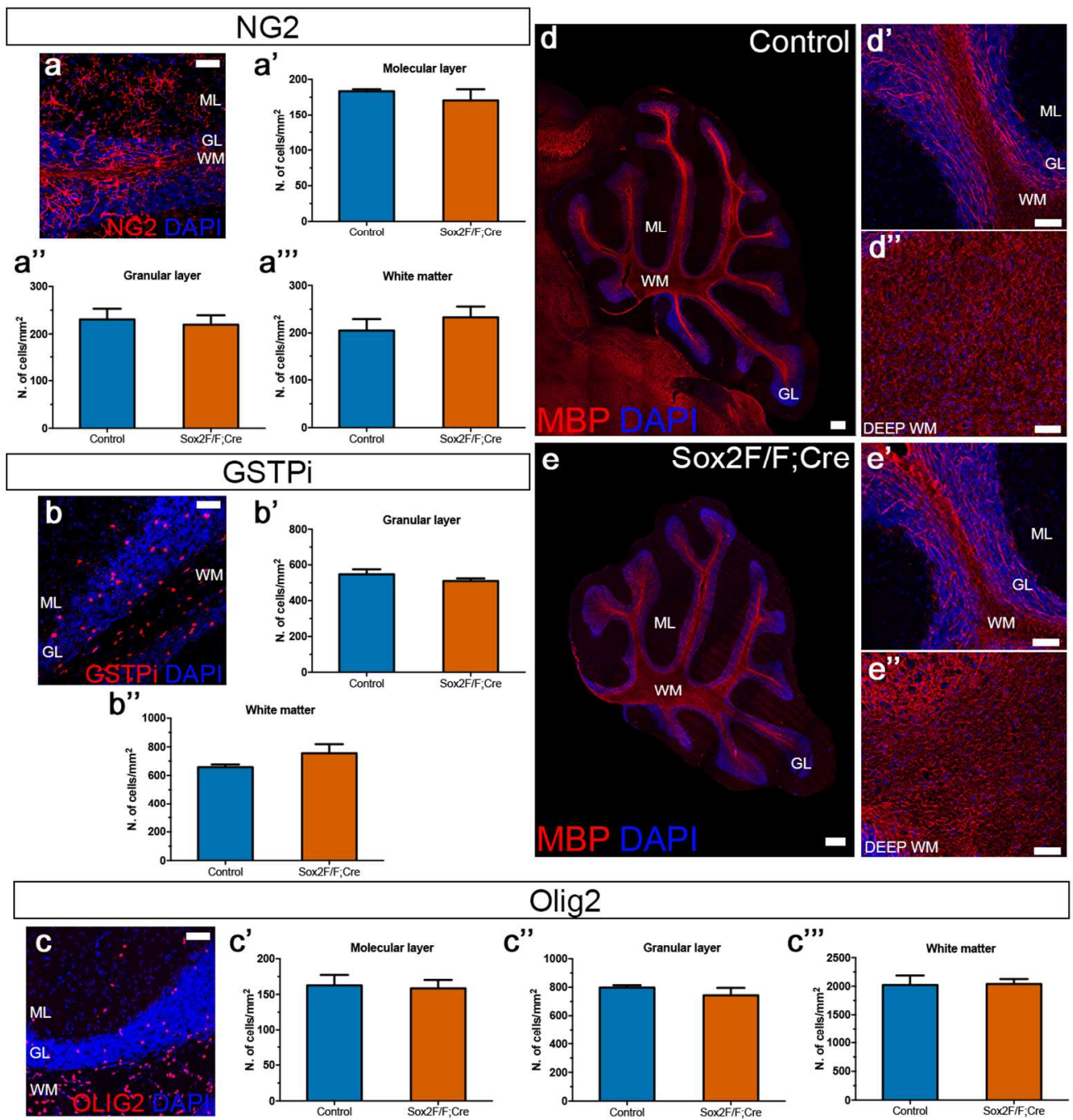


a

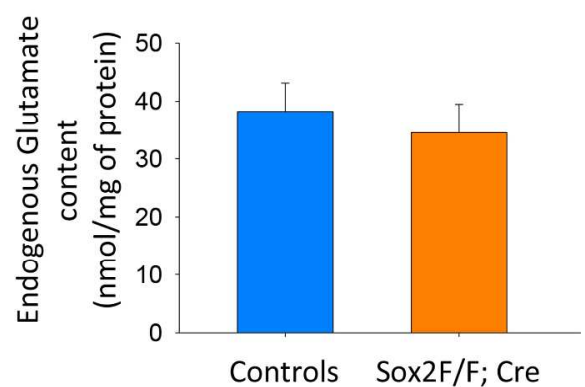

b

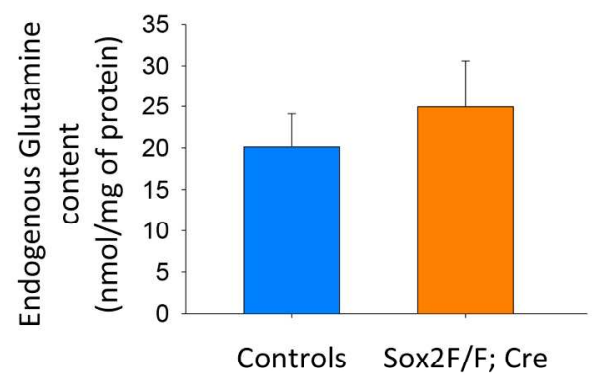

C

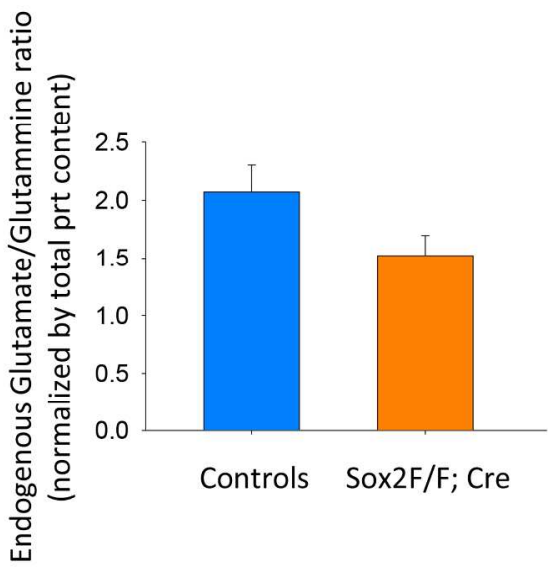

$199 \times 169 \mathrm{~mm}(300 \times 300$ DPI $)$ 


\begin{tabular}{|c|c|c|c|c|c|}
\hline Figure & Applied Test & P value & $\mathrm{F} / \mathrm{t}$ value & $\begin{array}{l}\text { Post hoc } \\
\text { analyses }\end{array}$ & Post hoc results \\
\hline $\begin{array}{l}\text { Fig. 1, rotarod } \\
\text { Sox2FF/F+, n=4 } \\
\text { Sox2F/+;Cre, } n=3 \\
\text { Sox2F/F;Cre, } n=10\end{array}$ & $\begin{array}{l}\text { Two-way } \\
\text { Anova }\end{array}$ & $\begin{array}{l}\text { Genotype: } \\
\mathrm{P}<0.0001\end{array}$ & $\begin{array}{l}\text { Genotype }(2, \\
14)= \\
70.54\end{array}$ & $\begin{array}{l}\text { Bonferroni's } \\
\text { Multiple } \\
\text { Comparison } \\
\text { Test }\end{array}$ & $\begin{array}{l}\text { Sox2F/F;Cre vs } \\
\text { Sox2FF/F+: } P<0.0012,3 \\
\text { months } \\
\mathrm{P}<0.054,7 \text { months } \\
\mathrm{P}<0.0015,6 \text { months } \\
\text { Sox2F/+;Cre } \\
\text { vs Sox2F/F;Cre } \\
\mathrm{P}<0.0012,3 \text { months }\end{array}$ \\
\hline $\begin{array}{l}\text { Fig. 1, beam (slips) } \\
\text { Sox } 2 F F / F+, n=4 \\
\text { Sox2F/+;Cre, } n=3 \\
\text { Sox } 2 F / F ; C r e, ~ n=10\end{array}$ & $\begin{array}{l}\text { Two-way } \\
\text { Anova }\end{array}$ & $\begin{array}{l}\text { Genotype: } \\
\mathrm{P}<0.0001\end{array}$ & $\begin{array}{l}\text { Genotype } \\
F(2,14)=73.49\end{array}$ & $\begin{array}{l}\text { Bonferroni's } \\
\text { Multiple } \\
\text { Comparison } \\
\text { Test }\end{array}$ & $\begin{array}{l}\text { Sox2F/F;Cre vs } \\
\text { Sox2FF/F+: } P<0.011,4,7,8 \\
\text { months } \\
\mathrm{P}<0.053,6 \text { months } \\
\mathrm{P}<0.0015 \text { months } \\
\text { Sox2F/F;Cre vs } \\
\text { Sox2F/+;Cre: } \\
\mathrm{P}<0.011,4 \text { months } \\
\mathrm{P}<0.05 \text { 6,8 months } \\
\mathrm{P}<0.0015 \text { months }\end{array}$ \\
\hline $\begin{array}{l}\text { Fig. 1, beam (time) } \\
\text { Sox2FF/F+, n=4 } \\
\text { Sox } 2 F /+; C r e, n=3 \\
\text { Sox } 2 F / F ; C r e, n=10\end{array}$ & $\begin{array}{l}\text { Two-way } \\
\text { Anova }\end{array}$ & $\begin{array}{l}\text { Genotype: } \\
\mathrm{P}<0.0001 \\
\text { Time: } \\
\mathrm{P}=0.002\end{array}$ & $\begin{array}{l}\text { Genotype } \\
F(2,14)=18.40 \\
\text { Time } F(7,14)= \\
6.16\end{array}$ & $\begin{array}{l}\text { Bonferroni's } \\
\text { Multiple } \\
\text { Comparison } \\
\text { Test }\end{array}$ & $\begin{array}{l}\text { Sox2F/F;Cre vs } \\
\text { Sox2FF/F+: and } \\
\text { Sox2F/F;Cre vs } \\
\text { Sox2F/+;Cre: } \\
\text { P<0.012 months }\end{array}$ \\
\hline $\begin{array}{l}\text { Fig. 2e } \\
\text { Sox2FF/F+, n=3 } \\
\text { Sox2F/+Cre, } n=3 \\
\text { Sox2F/F;Cre, } n=3\end{array}$ & $\begin{array}{l}\text { One-way } \\
\text { Anova }\end{array}$ & $\begin{array}{l}\text { Main effect of } \\
\text { genotype, } \\
\mathrm{P}=0.0026\end{array}$ & $(2,6)=18.93$ & $\begin{array}{l}\text { Bonferroni's } \\
\text { Multiple } \\
\text { Comparison } \\
\text { Test } \\
\end{array}$ & $\begin{array}{l}\text { Sox2FF/F+vs. } \\
\text { Sox2F/F;Cre, P=0.0045 } \\
\text { Sox2F/+;Cre vs. } \\
\text { Sox2F/F;Cre, P=0.0065 }\end{array}$ \\
\hline $\begin{array}{l}\text { Fig. } 2 \mathrm{f} \\
\text { Sox2FF/F+, } n=3 \\
\text { Sox } 2 F /+; C r e, n=3 \\
\text { Sox } 2 F / F ; C r e, n=3\end{array}$ & $\begin{array}{l}\text { One-way } \\
\text { Anova }\end{array}$ & $\begin{array}{l}\text { Main effect of } \\
\text { genotype, } \\
\mathrm{P}=0.014\end{array}$ & $(2,6)=24.14$ & $\begin{array}{l}\text { Bonferroni's } \\
\text { Multiple } \\
\text { Comparison } \\
\text { Test }\end{array}$ & $\begin{array}{l}\text { Sox2FF/F+vs. } \\
\text { Sox2F/F;Cre, } \mathrm{P}=0.016 \\
\text { Sox2F/+;Cre vs. } \\
\text { Sox2F/F;Cre, } \mathrm{P}=0.0078\end{array}$ \\
\hline $\begin{array}{l}\text { Fig. 2i } \\
\text { Lobule IV-V } \\
\text { Sox2FF/F+, n=3 } \\
\text { Sox2F/+Cre, } n=3 \\
\text { Sox2F/F;Cre, } n=3\end{array}$ & $\begin{array}{l}\text { One-way } \\
\text { Anova }\end{array}$ & $\begin{array}{l}\text { Main effect of } \\
\text { genotype, } \\
\mathrm{P}=0.0195\end{array}$ & $(2,6)=8.137$ & $\begin{array}{l}\text { Bonferroni's } \\
\text { Multiple } \\
\text { Comparison } \\
\text { Test }\end{array}$ & $\begin{array}{l}\text { Sox2FF/F+vs. } \\
\text { Sox2F/F;Cre, } \mathrm{P}=0.0344 \\
\text { Sox2F/+;Cre vs. } \\
\text { Sox2F/F;Cre, } \mathrm{P}=0.0442\end{array}$ \\
\hline $\begin{array}{l}\text { Fig. } 2 \mathrm{j} \\
\text { Lobule VIb } \\
\text { Sox2FF/F+, n=3 } \\
\text { Sox2F/+Cre, } n=3 \\
\text { Sox2F/F;Cre, } n=3\end{array}$ & $\begin{array}{l}\text { One-way } \\
\text { Anova }\end{array}$ & $\begin{array}{l}\text { Main effect of } \\
\text { genotype, } \\
\mathrm{P}=0.0084\end{array}$ & $(2,6)=11.76$ & $\begin{array}{l}\text { Bonferroni's } \\
\text { Multiple } \\
\text { Comparison } \\
\text { Test }\end{array}$ & $\begin{array}{l}\text { Sox2FF/F+vs. } \\
\text { Sox2F/F;Cre, } P=0.0259 \\
\text { Sox2F/+;Cre vs. } \\
\text { Sox2F/F;Cre, } P=0.0125\end{array}$ \\
\hline $\begin{array}{l}\text { Fig. 2k } \\
\text { Sox2FF/F+, n=3 } \\
\text { Sox } 2 F /+; C r e, n=3 \\
\text { Sox2F/F;Cre, } n=3\end{array}$ & $\begin{array}{l}\text { One-way } \\
\text { Anova }\end{array}$ & $\begin{array}{l}\text { IX, Main effect } \\
\text { of genotype, } \\
\mathrm{P}=0.0055 \\
\mathrm{X}, \text { Main effect } \\
\text { of genotype, } \\
\mathrm{P}=0.0124\end{array}$ & $\begin{array}{l}\text { IX, }(2,6)= \\
14.02 \\
X,(2,6)=9.965\end{array}$ & $\begin{array}{l}\text { Bonferroni's } \\
\text { Multiple } \\
\text { Comprison } \\
\text { Test }\end{array}$ & $\begin{array}{l}\text { IX, Sox2FF/F+ vs. } \\
\text { Sox2F/F;Cre, P=0.0076 } \\
\text { Sox2F/+;Cre vs. } \\
\text { Sox2F/F;Cre, P=0.0196 } \\
\text { X, Sox2FF/F+ vs. } \\
\text { Sox2F/F;Cre, P= } 0.00144\end{array}$ \\
\hline $\begin{array}{l}\text { Fig. } 2 \mathrm{n} \\
\text { VIa-VIb } \\
\text { Sox2FF/F+, n=3 } \\
\text { Sox2F/+;Cre, } n=3 \\
\text { Sox2F/F;Cre, } n=3 \\
\end{array}$ & $\begin{array}{l}\text { One-way } \\
\text { Anova }\end{array}$ & $\begin{array}{l}\text { Main effect of } \\
\text { genotype, } \\
\mathrm{P}=0.0411\end{array}$ & $F(2,6)=5.693$ & $\begin{array}{l}\text { Bonferroni's } \\
\text { Multiple } \\
\text { Comprison } \\
\text { Test }\end{array}$ & $\begin{array}{l}\text { Sox2F/+;Cre vs. } \\
\text { Sox2F/F;Cre, } P=0.0452\end{array}$ \\
\hline $\begin{array}{l}\text { Fig. 4s BG ectopia } 8 \\
\text { months } \\
\text { Sox } 2 \mathrm{~F} / \mathrm{F} ; \mathrm{Cre}, \mathrm{n}=5 \\
\text { Sox } 2 \mathrm{~F} /+; \mathrm{Cre}, \mathrm{n}=2 \\
\text { Sox } 2 \mathrm{FF} / \mathrm{F}+, \mathrm{n}=3 \\
\end{array}$ & $\begin{array}{l}\text { Student } \mathrm{T} \text { test } \\
\text { two tailed }\end{array}$ & $\mathrm{P}<0.0001$ & $t(8)=7.338$ & & \\
\hline $\begin{array}{l}\text { Fig. 4t BG density in } \\
\text { PCL } \\
\text { mutants: } \\
\text { Sox2F/F;Cre, } n=3 \\
\text { controls: } \\
\text { Sox } 2 F /+; C r e, n=3\end{array}$ & $\begin{array}{l}\text { Student T test } \\
\text { two tailed }\end{array}$ & $\mathrm{P}=0.0179$ & $t(7)=3.075$ & & \\
\hline
\end{tabular}




\begin{tabular}{|c|c|c|c|c|c|}
\hline Sox $2 F F / F+, n=3$ & & & & & \\
\hline $\begin{array}{l}\text { Fig. 4u BG/PCL } \\
\text { mutants: } \\
\mathrm{n}=3 \text { Sox } 2 \mathrm{~F} / \mathrm{F} ; \mathrm{Cre} \\
\text { controls: } \\
\mathrm{n}=2 \text { Sox } 2 \mathrm{~F} /+ \text {;Cre } \\
\mathrm{n}=3 \text {, Sox } 2 \mathrm{FF} / \mathrm{F}+\end{array}$ & $\begin{array}{l}\text { Student } \mathrm{T} \text { test } \\
\text { two tailed }\end{array}$ & $\mathrm{P}=0.0014$ & $t(7)=5.080$ & & \\
\hline 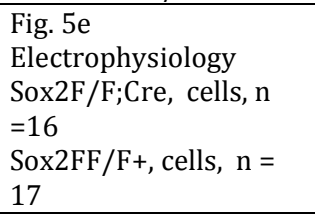 & $\begin{array}{l}\text { Kolmogorov- } \\
\text { Smirnov test }\end{array}$ & $\mathrm{P}<0.0001$ & $\mathrm{D}=0.68$ & & \\
\hline $\begin{array}{l}\text { Fig. 6k BG ectopia Tx } \\
\text { P2, } 30 \text { days survival } \\
\text { mutants: } \\
\text { Sox2F/F;CreERT2, n=3 } \\
\text { controls: } \\
\text { Sox2F/+;CreERT2, n=1, } \\
\text { Sox2FF or Sox2F/+, } \\
n=2\end{array}$ & $\begin{array}{l}\text { Student } \mathrm{T} \text { test } \\
\text { two tailed }\end{array}$ & $\mathrm{P}=0,0011$ & $t(4)=8.478$ & & \\
\hline $\begin{array}{l}\text { Fig. 6n ectopia Tx P2 vs } \\
\text { Tx P8-60 vs controls, } 8 \\
\text { months survival } \\
\text { mutants: } \\
\text { Sox2F/F;CreERT2-P2, } \\
\text { n=4 } \\
\text { Sox2F/F;CreERT2- } \\
\text { P8/60, n=3 } \\
\text { controls: } \\
\text { Sox2F/+;CreERT2-P2, } \\
n=2 \text {, } \\
\text { Sox2FF or Sox2F/+P2, } \\
n=2\end{array}$ & $\begin{array}{l}\text { One way } \\
\text { Anova }\end{array}$ & $\mathrm{P}=0,0066$ & $\begin{array}{l}\text { Genotype }(2, \\
8)= \\
10.03\end{array}$ & $\begin{array}{l}\text { Bonferroni's } \\
\text { Multiple } \\
\text { Comparison } \\
\text { Test }\end{array}$ & $\begin{array}{l}\text { Sox2F/F;CreERT2-P2 vs } \\
\text { controls, P=0.0114 } \\
\text { Sox2F/F;CreERT2-P8/60 } \\
\text { vs } \\
\text { controls, } P=0.0209\end{array}$ \\
\hline $\begin{array}{l}\text { Fig. 7a beam (slips), } \\
\text { both sexes } \\
\text { Sox2F/F;CreERT2, } \\
\text { TxP8-60, n=9 } \\
\text { Sox2F/F;CreERT2, no } \\
\text { Tx, n=14 }\end{array}$ & $\begin{array}{l}\text { Two-way RM } \\
\text { Anova }\end{array}$ & $\begin{array}{l}\text { Main effect of } \\
\text { genotype, } \\
\mathrm{P}<0.0454\end{array}$ & $F(1,21)=4.526$ & $\begin{array}{l}\text { Bonferroni's } \\
\text { Multiple } \\
\text { Comparison } \\
\text { Test }\end{array}$ & month $1, \mathrm{P}=0.0128$ \\
\hline $\begin{array}{l}\text { Fig. 7b beam (time) } \\
\text { Sox2F/F;CreERT2, } \\
\text { TxP8-60, n=9 } \\
\text { Sox2F/F;CreERT2, no } \\
\text { Tx, n=14 }\end{array}$ & $\begin{array}{l}\text { Two-way RM } \\
\text { Anova }\end{array}$ & $\begin{array}{l}\text { Main effect of } \\
\text { genotype, } \\
\mathrm{P}<0.0333 \\
\text { Main effect of } \\
\text { time, } \\
\mathrm{P}<0.0001\end{array}$ & $\begin{array}{l}F_{\text {genoype }} \\
(1,21)=5.192 \\
F_{\text {time }} \\
(3,63)=8.330\end{array}$ & $\begin{array}{l}\text { Bonferroni's } \\
\text { Multiple } \\
\text { Comparison } \\
\text { Test }\end{array}$ & $\begin{array}{l}\text { Genotype, month } 3 \text {, } \\
\mathrm{P}=0.0288 \\
\text { Time, controls: } \\
\text { month } 2 \text { vs } 4, \mathrm{P}=0.0050 \text {; } \\
\text { month } 3 \text { vs } 4, \mathrm{P}=0.049 \\
\text { mutants: } \\
\text { month } 1 \text { vs } 4, \mathrm{P}=0.0042 \text {; } \\
\text { month } 2 \text { vs } 4, \mathrm{P}=0.0069\end{array}$ \\
\hline $\begin{array}{l}\text { Fig. 7d Rotarod, males } \\
\text { Sox2F/F;CreERT2, } \\
\text { TxP8-60, n=3 } \\
\text { Sox2F/F;CreERT2, no } \\
\text { Tx, n=7 }\end{array}$ & $\begin{array}{l}\text { Two-way RM } \\
\text { Anova }\end{array}$ & $\begin{array}{l}\text { Main effect of } \\
\text { interaction } \\
\text { genotype } \mathrm{x} \\
\text { time, } \\
\mathrm{P}<0.0001\end{array}$ & $F(3,24)=17.05$ & $\begin{array}{l}\text { Bonferroni's } \\
\text { Multiple } \\
\text { Comparison } \\
\text { Test }\end{array}$ & month $2, \mathrm{P}=0.0131$ \\
\hline Fig. 8 Vmax & $\begin{array}{l}\text { Student T test } \\
\text { two tailed }\end{array}$ & $\mathrm{P}=0.019$ & $t(8)=-3.195$ & & \\
\hline
\end{tabular}

Supplementary Table 1. Details of statistical analyses. In most cases only comparisons

leading to $\mathrm{P}<0.05$ are reported; $\mathrm{n}=$ number of animals (unless differently stated). $\mathrm{RM}$, repeated measures. 
John Wiley \& Sons, Inc. 


\begin{tabular}{|c|c|c|c|c|c|}
\hline Dataset & Time & Genotype & Mean \pm SEM & $\mathrm{n}$, animals & Student $t$ test \\
\hline \multirow[t]{2}{*}{$\%$ of ectopic BG } & 8 months & Sox $2 \mathrm{~F} /+$;Cre & $5.179 \pm 1.298$ & 2 & \multirow[t]{2}{*}{$\begin{array}{c}\mathrm{P}=0.6445 \\
\mathrm{t}(3)=0.5111\end{array}$} \\
\hline & & Sox2FF/F+ & $6.081 \pm 0.7485$ & 3 & \\
\hline \multirow[t]{2}{*}{ BG density in PCL } & 8 months & Sox $2 \mathrm{~F} /+; \mathrm{Cre}$ & $6141 \pm 396.4$ & 3 & \multirow{2}{*}{$\begin{array}{l}\mathrm{P}=0.2233 \\
\mathrm{t}(4)=1440\end{array}$} \\
\hline & & Sox2FF/F+ & $6781 \pm 201.1$ & 3 & \\
\hline \multirow[t]{2}{*}{$\mathrm{BG} / \mathrm{PC}$} & 8 months & Sox $2 \mathrm{~F} /+; \mathrm{Cre}$ & $3.518 \pm 0.1780$ & 3 & \multirow[t]{2}{*}{$\begin{array}{l}\mathrm{P}=0.1252 \\
\mathrm{t}(4)=1.935\end{array}$} \\
\hline & & Sox2FF/F+ & $3.939 \pm 0.1256$ & 3 & \\
\hline \multirow[t]{2}{*}{$\%$ of ectopic BG Tx P2 } & $\mathrm{P} 30$ & Sox2FF/F+ & $6.215 \pm 0.4674$ & 2 & \multirow[t]{2}{*}{$\mathrm{n} / \mathrm{a}$} \\
\hline & & Sox $2 \mathrm{~F} /+$;CreERT2 & 6.63 & 1 & \\
\hline \multirow[t]{2}{*}{$\%$ of ectopic BG Tx P2 } & 8 months & Sox2FF/F+ & $\begin{array}{c}2.118 \pm 0 \\
6345\end{array}$ & 2 & \multirow[t]{2}{*}{$\begin{array}{l}\mathrm{P}=0.2992 \\
\mathrm{t}(2)=1.389\end{array}$} \\
\hline & & Sox2F/+;CreERT2 & $4.207 \pm 1.363$ & 2 & \\
\hline \multirow[t]{2}{*}{ PCs density } & 8 months & Sox2FF/F+ & $1423 \pm 56,26$ & 3 & \multirow{2}{*}{$\begin{array}{c}\mathrm{P}=0.9798 \\
\mathrm{t}(3)=0.02749\end{array}$} \\
\hline & & Sox $2 F /+$;Cre & $1428 \pm 222,2$ & 2 & \\
\hline \multirow[t]{2}{*}{ ML interneurons density } & 8 months & Sox $2 \mathrm{FF} / \mathrm{F}+$ & $859,7 \pm 71,81$ & 2 & \multirow[t]{2}{*}{$\begin{array}{l}\mathrm{P}=0.1412 \\
\mathrm{t}(2)=2.370\end{array}$} \\
\hline & & Sox $2 \mathrm{~F} /+$;Cre & $685,7 \pm 15,35$ & 2 & \\
\hline \multirow[t]{2}{*}{ GL astrocytes density } & P19 & Sox2FF/F+ & $821,4 \pm 84,98$ & 2 & \multirow[t]{2}{*}{$\mathrm{n} / \mathrm{a}$} \\
\hline & & Sox $2 \mathrm{~F} /+; \mathrm{Cre}$ & 761,1 & 1 & \\
\hline \multirow[t]{2}{*}{ WM astrocytes density } & P19 & Sox2FF/F+ & $1743 \pm 692,5$ & 2 & \multirow[t]{2}{*}{$\mathrm{n} / \mathrm{a}$} \\
\hline & & Sox $2 \mathrm{~F} /+$;Cre & 974,8 & 1 & \\
\hline
\end{tabular}

Supplementary Table 2. Average numerical values obtained in immunofluorescence experiments, and statistical analysis. 